\title{
A new scheme for sulphur dioxide retrieval from IASI measurements: application to the Eyjafjallajökull eruption of April and May 2010
}

\author{
E. Carboni ${ }^{1}$, R. Grainger ${ }^{1}$, J. Walker ${ }^{1,2}$, A. Dudhia ${ }^{1}$, and R. Siddans ${ }^{3}$ \\ ${ }^{1}$ Sub-Department of Atmospheric, Oceanic and Planetary Physics, University of Oxford, Oxford OX1 3PU, UK \\ ${ }^{2}$ European Space Agency, Harwell Centre, Oxfordshire, OX11 0QX, UK \\ ${ }^{3}$ Rutherford Appleton Laboratory, Didcot, UK \\ Correspondence to: E. Carboni (elisa@atm.ox.ac.uk)
}

Received: 17 April 2012 - Published in Atmos. Chem. Phys. Discuss.: 8 May 2012

Revised: 12 November 2012 - Accepted: 26 November 2012 - Published: 3 December 2012

\begin{abstract}
A new optimal estimation algorithm for the retrieval of sulphur dioxide $\left(\mathrm{SO}_{2}\right)$ has been developed for the Infrared Atmospheric Sounding Interferometer (IASI) using the channels between $1000-1200$ and $1300-1410 \mathrm{~cm}^{-1}$. These regions include the two $\mathrm{SO}_{2}$ absorption bands centred at about 8.7 and $7.3 \mu \mathrm{m}$ (the $\nu_{1}$ and $\nu_{3}$ bands respectively). The retrieval assumes a Gaussian $\mathrm{SO}_{2}$ profile and returns the $\mathrm{SO}_{2}$ column amount in Dobson units and the altitude of the plume in millibars $(\mathrm{mb})$. Forward modelled spectra (against which the measurements are compared) are based on the Radiative Transfer for TOVS (RTTOV) code. In our implementation RTTOV uses atmospheric profiles from European Centre for Medium-Range Weather Forecasts (ECMWF) meteorological data. The retrieval includes a comprehensive error budget for every pixel derived from an error covariance matrix that is based on the $\mathrm{SO}_{2}$-free climatology of the differences between the IASI and forward modelled spectra. The IASI forward model includes the ability to simulate a cloud or ash layer in the atmosphere. This feature is used to illustrate that: (1) the $\mathrm{SO}_{2}$ retrieval is not affected by underlying cloud but is affected if the $\mathrm{SO}_{2}$ is within or below a cloud layer; (2) it is possible to discern if ash (or other atmospheric constituents not considered in the error covariance matrix) affects the retrieval using quality control based on the fit of the measured spectrum by the forward modelled spectrum. In this work, the algorithm is applied to follow the behaviour of $\mathrm{SO}_{2}$ plumes from the Eyjafjallajökull eruption during April and May 2010. From 14 April to 4 May (during Phase I and II of the eruption) the total amount of $\mathrm{SO}_{2}$ present in the atmo-
\end{abstract}

sphere, estimated by IASI measurements, is generally below $0.02 \mathrm{Tg}$. During the last part of the eruption (Phase III) the values are an order of magnitude higher, with a maximum of $0.18 \mathrm{Tg}$ measured on the afternoon of 7 May.

\section{Introduction}

The magmatic processes of an active volcano (during both quiescent and eruptive phases) can be monitored, and potentially explained, by observations of volcanic emission into the atmosphere. Particularly important is the emission of sulphur dioxide $\left(\mathrm{SO}_{2}\right)$ as it is typically the third most abundant gas emitted by volcanoes after water vapour and $\mathrm{CO}_{2}$ (Symonds et al., 1994). Improved satellite remote sensing of $\mathrm{SO}_{2}$ is important because this can allow the monitoring of active and dangerous volcanoes that are in remote areas and not monitored by ground-based instruments. Moreover, the volcanic $\mathrm{SO}_{2}$ plume can be used as a proxy for volcanic ash within the first few hours of its release, when the effect of wind shear and gravitation have not separated the ash plume from the $\mathrm{SO}_{2}$. However this needs to be done with extreme caution as several eruptions show separation of the two species (Prata and Kerkmann, 2007; Prata et al., 2010; Thomas and Prata, 2011; Sears et al., 2012).

During the past thirty years, satellite observations using spectral bands containing $\mathrm{SO}_{2}$ absorption in the ultraviolet (UV) or the infrared (IR) have been used to monitor explosive volcanic activity e.g. Total Ozone Mapping 
Spectrometer, TOMS, data from 1979; TIROS Operational Vertical Sounder, TOVS, data from 1978 (Carn et al., 2003; Prata et al., 2003). Satellite retrievals can be a useful source of information about volcanic eruptions, but are less sensitive to low amounts of $\mathrm{SO}_{2}$ (e.g. quiescent degassing) than ground-based monitoring. In recent years more advanced, high resolution spectrometers, such as the Ozone Monitoring Instrument (OMI) on-board AURA from 2004, the Infrared Atmospheric Sounding Interferometer (IASI) and the Global Ozone Monitoring Experiment-2 (GOME-2) on-board the Meteorological Operational satellite (MetOp-A from 2006), have made possible the study of quiescent volcanic activity (Carn et al., 2008).

Near-real time estimates of $\mathrm{SO}_{2}$ are available globally for hazard warning purposes (e.g. from OMI, GOME-2, Atmospheric Infrared Sounder, AIRS and IASI). The accuracy of these data is restricted by the assumptions that need to be made (e.g. the altitude of the volcanic plume) in order to provide a fast (near-real time) system. Furthermore, these data do not usually provide reliable estimates of the associated error. As shown by Thomas et al. (2009) the total tonnages retrieved by different UV and IR sensors are variable and highly dependent on the prescribed plume altitude. They can be useful for aviation hazard warning but are less reliable for scientific studies.

Satellite infrared spectrometers (such as AIRS, the Tropospheric Emission Spectrometer, TES, or IASI) can measure volcanic $\mathrm{SO}_{2}$ in three spectral regions; around 4.0, 7.3 and $8.7 \mu \mathrm{m}$ (called, respectively, the $\nu_{1}+\nu_{3}, \nu_{3}$ and $\nu_{1}$ absorption bands). The $4.0 \mu \mathrm{m}$ absorption feature $\left(v_{1}+v_{3}\right)$ is weak, and reflected solar radiation is significant during daytime. It has been used for IASI retrievals when large amounts of $\mathrm{SO}_{2}$ saturate the signal in the other absorption bands (Karagulian et al., 2010).

The $7.3 \mu \mathrm{m}$ feature ( $\nu_{3}$ band) is the strongest of the three bands. It is collocated with a strong water vapour absorption band and, as a consequence it is not very sensitive to emission from the surface and lower atmospheric layers. Higher in the atmosphere it does contains information on the $\mathrm{SO}_{2}$ vertical profile. The $7.3 \mu \mathrm{m}$ feature has been used to retrieve $\mathrm{SO}_{2}$ amount from AIRS data (Carn et al., 2005; Prata and Bernardo, 2007) with an assumed plume altitude. IASI measurements in this band have been used in optimal estimation retrievals (Clarisse et al., 2008), in a brightness temperature difference alert system (ULB MetOp/IASI SO $\mathrm{S}_{2}$ Alerts), and in a fast $\mathrm{SO}_{2}$ retrieval with an assumed plume altitude above $500 \mathrm{mb}$ (Clarisse et al., 2012).

The $8.7 \mu \mathrm{m}$ absorption feature ( $v_{1}$ band) also contains information on the $\mathrm{SO}_{2}$ amount for lower tropospheric plumes. This region is an atmospheric window (relatively high transmittance) and, at IASI spectral resolution, does not contain significant spectral information about the plume altitude/profile. Nevertheless it is probably the most useful region for monitoring those volcanoes characterized by continuous quiescent degassing (Realmuto et al., 1994, 1997; Real- muto, 2000). The $8.7 \mu \mathrm{m}$ feature has been used to retrieve the total $\mathrm{SO}_{2}$ amount and profile from TES data (Clerbaux et al., 2008). This is possible as TES has sufficient spectral resolution to resolve the change in $\mathrm{SO}_{2}$ line-width with pressure.

Ground-based measurements of $\mathrm{SO}_{2}$ are usually available while volcanoes are in a degassing/quiescent mode. Some recent work (Henney et al., 2012; Merucci et al., 2011) compares ground-based $\mathrm{SO}_{2}$ concentrations with satellite data. However ground-based data is generally unavailable during explosive eruptions when large quantities of $\mathrm{SO}_{2}$ are released. This makes the validation of satellite measurements of large $\mathrm{SO}_{2}$ emissions challenging, for example OMI validation is currently limited to one small eruption plume (less than 3 Dobson Units (DU) of $\mathrm{SO}_{2}$ ) located in the UTLS.

In this paper an optimal estimation scheme is described that retrieves $\mathrm{SO}_{2}$ from nadir satellite thermal infrared measurements of the $v_{3}$ and $v_{1}$ absorption bands. This retrieval uses a new approach to compute the total error covariance matrix, $\mathbf{S}_{\epsilon}$. In this method any differences between the IASI and simulated spectrum, not related to $\mathrm{SO}_{2}$, are included in the total error covariance matrix, allowing a comprehensive error budget to be computed for every pixel. This paper has three main objectives: (1) to describe the algorithm; (2) to assess the performance and data quality of the $\mathrm{SO}_{2}$ retrieval from IASI measurements; (3) to apply the new retrieval to analyse the volcanic eruption of Eyjafjallajökull during April and May 2010.

\section{MetOp-A IASI data}

IASI is on-board MetOp-A, a European meteorological satellite that has been operational from 2007. MetOp-A is the first of three satellites that are planned to operate for fourteen years (MetOp-B was lauched on 17 September 2013). It crosses the equator on the descending node at 9:30 a.m. local time. IASI is a Fourier transform spectrometer that covers the spectral range 645 to $2760 \mathrm{~cm}^{-1}(3.62-15.5 \mu \mathrm{m})$ with a spectral sampling of $0.25 \mathrm{~cm}^{-1}$ and an apodized spectral resolution of $0.5 \mathrm{~cm}^{-1}$ (Blumstein et al., 2004). It is specified to have a radiometric accuracy of $0.25-0.58 \mathrm{~K}$ and a field-of-view of $12 \mathrm{~km}$ at nadir. It has a $2200 \mathrm{~km}$ wide swath and achieves near uniform global coverage in $12 \mathrm{~h}$ (although there are some gaps between orbits near the Equator). Observations are collocated with the Advanced Very High Resolution Radiometer (AVHRR) that provides complementary visible/near infrared measurements. IASI makes a nadir observation of the earth simultaneously with Global Ozone Monitoring Experiment (GOME-2) also on-board MetOp-A. GOME-2 is an UV spectrometer that measures $\mathrm{SO}_{2}$ in the UV absorption band and has been used for both DOAS (Rix et al., 2012) and optimal estimation retrievals of $\mathrm{SO}_{2}$ (Nowlan et al., 2011). More information on IASI can be founded in Clerbaux et al. (2009). This work uses IASI level 1c data (geolocated and apodized spectra), obtained from 
both the British Atmospheric Data Centre (BADC) archive and EUMETSAT Unified Meteorological Archive Facility (UMARF) archive.

\section{Method}

\subsection{Optimal Estimation}

An optimal estimation (OE) retrieval (Rodgers, 2000) was used to estimate the column amount and altitude of $\mathrm{SO}_{2}$ from IASI spectra. Briefly, the OE retrieval seeks a minimum for a cost function $J$ defined by

$J=(\boldsymbol{y}-\mathbf{F}(\boldsymbol{x}))^{\mathrm{T}} \mathbf{S}_{\mathrm{y}}^{-1}(\boldsymbol{y}-\mathbf{F}(\boldsymbol{x}))+\left(\boldsymbol{x}-\boldsymbol{x}_{\mathrm{a}}\right)^{\mathrm{T}} \mathbf{S}_{\mathrm{a}}^{-1}\left(\boldsymbol{x}-\boldsymbol{x}_{\mathrm{a}}\right)$

where $\boldsymbol{y}$ contains the measurements, typically spectral radiance or brightness temperatures; $\mathbf{S}_{\mathrm{y}}$ is the noise covariance matrix of the measurements; and $\boldsymbol{x}$ is the state vector, the vector of parameters to be retrieved. In principle $\boldsymbol{x}$ contains all atmospheric and surface parameters that affect these radiances and which are imperfectly known (e.g. water vapour and temperature profiles, cloud properties and many other minor species profiles, as well as $\mathrm{SO}_{2}$ ). The simulated measurements $\mathbf{F}(\boldsymbol{x})$ are obtained with the forward model. The a priori state vector $\boldsymbol{x}_{\mathrm{a}}$ represent our knowledge of the state before the measurement is made while the a priori error covariance matrix $\mathbf{S}_{\mathrm{a}}$ represents the precision of this knowledge. Finding the minimum of $J$ corresponds to finding the state vector $\boldsymbol{x}$ that maximizes the probability of obtaining the measurement $\boldsymbol{y}$ and that is consistent with the a priori estimate.

\subsection{Simplifying the problem}

Minimising Eq. (1) for the all the IASI spectral measurements (8641 channels) and a state vector that included the gas profile for tens of species would be computationally expensive and impractical for studies that involve the analysis of thousands of spectra. However: (1) the state of many of these variables is of no interest; (2) $\mathrm{SO}_{2}$ is very rarely present in significant amounts in the IASI spectra (except during volcanic eruptions and degassing regions); (3) water vapour and temperatures are well predicted by meteorological data; (4) other gases and atmospheric constituents (like clouds and ash) have features which are spectrally uncorrelated with $\mathrm{SO}_{2}$. The retrieval problem can be greatly simplified by considering only a few elements in the state vector and including the variability coming from the remaining parameters (that are not of interest) in a total error covariance matrix, $\mathbf{S}_{\epsilon}$. In this way $\mathbf{S}_{\epsilon}$ will include: the instrumental errors (IASI noise), the forward model errors (imperfect radiative transfer), errors in meteorological fields and all the errors due to the lack of knowledge of the parameters that affect the radiance; e.g. the errors due to the non-perfect representation of gas absorption (both profile and spectroscopy), and especially errors due to presence of a cloud layer. The retrieval then involves minimizing a new the cost function

$$
\begin{aligned}
J^{\prime}= & (\boldsymbol{y}-\mathbf{F}(\boldsymbol{x}, \boldsymbol{b})-\boldsymbol{c})^{\mathrm{T}} \mathbf{S}_{\epsilon}^{-1}(\boldsymbol{y}-\mathbf{F}(\boldsymbol{x}, \boldsymbol{b})-\boldsymbol{c}) \\
& +\left(\boldsymbol{x}-\boldsymbol{x}_{\mathrm{a}}\right)^{\mathrm{T}} \mathbf{S}_{\mathrm{a}}^{-1}\left(\boldsymbol{x}-\boldsymbol{x}_{\mathrm{a}}\right)
\end{aligned}
$$

where $\boldsymbol{x}$ is the reduced state vector, $\boldsymbol{b}$ are those elements of the atmospheric state that are needed by the forward model but are not retrieved and $\boldsymbol{c}$ is a bias term that represents the mean difference between the measurements $\boldsymbol{y}$ and the simulated spectra $\mathbf{F}(\boldsymbol{x}, \boldsymbol{b})$ derived from $\mathrm{SO}_{2}$ free scenes.

A further simplification can be made by modelling a continuous gas profile with an analytic function (Rodgers, 2000). Here the $\mathrm{SO}_{2}$ volume mixing ratio $x_{\mathrm{SO}_{2}}$ is assumed to have a Gaussian profile shape as function of pressure $p$ and described by

$x_{\mathrm{SO}_{2}}(p)=\frac{A}{\sqrt{2 \pi \sigma_{\mathrm{SO}_{2}}^{2}}} e^{-(p-p \max )^{2} / 2 \sigma_{\mathrm{SO}_{2}}^{2}}$

where $p_{\max }$ is the mean plume altitude, $\sigma_{\mathrm{SO}_{2}}$ is the vertical spread of the plume and $A$ is the total amount of $\mathrm{SO}_{2}$ in the plume. Motivation for this choice of vertical profile comes from Carboni and Grainger (2009) where it was found that IASI spectra contain between two and three degrees-offreedom for $\mathrm{SO}_{2}$. For large eruptions there are three degreesof-freedom and all three parameters can be used in the state vector. For small to intermediate eruptions (such as the one analysed in this paper) there is insufficient information in the IASI spectra to retrieve three quantities so $A$ and $p_{\mathrm{SO}_{2}}$ are retrieved while the $\sigma_{\mathrm{SO}_{2}}$ is fixed at $100 \mathrm{mb}$.

The state vector $\boldsymbol{x}$ is defined as:

$\boldsymbol{x}=\left[A, p_{\mathrm{SO}_{2}}, \sigma_{\mathrm{SO}_{2}}, T_{\mathrm{S}}\right]$.

In the current problem the state vector $\boldsymbol{x}$ is pratically reduced to the $\mathrm{SO}_{2}$ column amount, the altitude of the plume, and the surface temperature (i.e. the vertical spread of the plume is highly constrained to $100 \mathrm{mb}$, with $1 \mathrm{mb}$ a priori error). Additional knowledge of the atmospheric state comes from European Centre for Medium-Range Weather Forecasts (ECMWF) profiles of temperature, pressure and water vapour linearly interpolated to the time and location of the IASI measurement. Ozone, $\mathrm{N}_{2} \mathrm{O}$ and $\mathrm{CH}_{4}$ are taken from the standard atmosphere defined in GOMETRAN (Rozanov et al., 1997) and are not varied.

The final simplification of the problem is to reduce the measurement vector to the range of wavelengths which contain information on $\mathrm{SO}_{2}$. In this work the retrievals used all the IASI channels between 1000-1200 and 1300$1410 \mathrm{~cm}^{-1}$. This reduced the number of elements that needed to be simulated by the forward model from 8641 (the full IASI spectrum) to 1242 .

\subsection{Fast forward model}

The fast forward model simulates the IASI brightness temperature (BT) spectrum using Radiative Transfer for TOVS 
(RTTOV) v.9 (Saunders et al., 1999) driven by the atmospheric state. RTTOV considers an atmosphere divided into 90 layers (i.e. 91 levels), where the first level is the top of the atmosphere (TOA). RTTOV is used to calculate the radiances, $L(i)$, and brightness temperatures, $T_{\mathrm{B}}(i)$, at the TOA for every channel, $i$. As described in Matricardi (2008) the standard version of RTTOV uses a set of coefficients which weight a set of "predictors" to give the instrument spectral response function convolved with the transmission from a level in the atmosphere to space. The predictors are pre-defined functions of the concentrations of trace gases, temperature, pressure and viewing geometry. These are determined by performing "exact" calculations of the transmissions using an accurate line-by-line model for a wide range of atmospheric and viewing conditions. A regression scheme is then used to optimise the values of the coefficients to give the minimal difference between the line-by-line modelled transmissions and those predicted by the fast model. The standard RTTOV distribution provides coefficients which allow the variability of $\mathrm{H}_{2} \mathrm{O}, \mathrm{CO}_{2}, \mathrm{CO}, \mathrm{O}_{3}, \mathrm{~N}_{2} \mathrm{O}$ and $\mathrm{CH}_{4}$ to be simulated. Other gases are modelled with fixed profiles.

For the current study the $\mathrm{CO}$ coefficients were replaced by coefficients for $\mathrm{SO}_{2}$ in the spectral ranges 1094.75$1232 \mathrm{~cm}^{-1}$ and $1325-1449.5 \mathrm{~cm}^{-1}$. The $\mathrm{SO}_{2}$ feature around $4 \mu \mathrm{m}$ was not modelled. The modified set of coefficients were based on exact calculations of transmission to space from 100 specific pressure levels using the Reference Forward Model (RFM, see http://www.atm.ox.ac.uk/RFM/). The coefficients were formed using a regression approach similar to that used in the standard scheme. The same 83 atmospheres (profiles for $\mathrm{H}_{2} \mathrm{O}, \mathrm{CO}_{2}, \mathrm{O}_{3}, \mathrm{~N}_{2} \mathrm{O}$ and $\mathrm{CH}_{4}$ ) used to derive the standard coefficients were augmented by $\mathrm{SO}_{2}$ profiles. The $\mathrm{SO}_{2}$ profile for each atmosphere was chosen randomly from a set of Gaussian profiles constructed with the $\mathrm{SO}_{2}$ column amount in the range 0.1 to $100 \mathrm{DU}$, the $\mathrm{SO}_{2}$ peak chosen from 3, 9, 15 and $21 \mathrm{~km}$ and with a vertical spread of $6 \mathrm{~km}$. The calculation is described in more detail in STFC (2011).

\subsection{Weighting functions}

The minimization routine uses the Levenberg-Marquard numerical iteration method. This approach uses the weighting function matrix $\mathbf{K}$, that contains the derivatives of simulated spectral measurement (index $i$ ) with respect to each element (index $j$ ) of the state vector.

The first two columns of the weighting function matrix (corresponding to the spectral sensitivity for $\mathrm{SO}_{2}$ total column amount and plume altitude) can be efficiently calculated by employing the chain rule i.e.

$$
\begin{aligned}
\mathbf{K}(i, 1) & =\frac{\partial T_{\mathrm{B}}(i)}{\partial \boldsymbol{x}_{\mathrm{SO}_{2}}} \frac{\partial \boldsymbol{x}_{\mathrm{SO}_{2}}}{\partial A} \\
\mathbf{K}(i, 2) & =\frac{\partial T_{\mathrm{B}}(i)}{\partial \boldsymbol{x}_{\mathrm{SO}_{2}}} \frac{\partial \boldsymbol{x}_{\mathrm{SO}_{2}}}{\partial p_{\mathrm{SO}_{2}}}
\end{aligned}
$$

where $\boldsymbol{x}_{\mathrm{SO}_{2}}$ is the $\mathrm{SO}_{2}$ mixing ratio profile. The third column of the weighting function matrix is

$$
\mathbf{K}(i, 3)=\frac{\partial T_{\mathrm{B}}(i)}{\partial T_{\mathrm{S}}}
$$

Figures $1 \mathrm{a}$ and $\mathrm{b}$ show the brightness temperature and surface to TOA transmittance spectra obtained for a reference clear atmosphere whose gas concentrations come from the SCIATRAN radiative transfer package and is based on 2-D chemo-dynamical model output (Bruhl and Crutzen, 1993). The reference clear atmosphere is representative of a cloudfree mid-latitude $\left(55^{\circ} \mathrm{N}\right)$ atmosphere. Figure $1 \mathrm{c}$ shows the surface temperature weighting function. Where the transmittance is high (Fig. 1b) the measured brightness temperature that will be influenced by a change in surface temperature (as shown in Fig. 1c) or by the addition of an underlying cloud or ash layer.

It is informative to examine the weighting functions of the IASI spectra to the temperature and trace gas profiles. Figures $1 \mathrm{~d}-\mathrm{i}$ show the weightings for temperature $\mathbf{K}_{\mathrm{T}}$, water vapour $\mathbf{K}_{\mathrm{H}_{2} \mathrm{O}}$, ozone $\mathbf{K}_{\mathrm{O}_{3}}$, sulphur dioxide $\mathbf{K}_{\mathrm{SO}_{2}}$, nitrous oxide $\mathbf{K}_{\mathrm{N}_{2} \mathrm{O}}$ and methane $\mathbf{K}_{\mathrm{CH}_{4}}$ respectively. The plot of the temperature weighting function (Fig. 1d) shows that the measured brightness temperature is principally affected by the temperature profile between 0 and $10 \mathrm{~km}$. The strongest sensitivity occurs for $v>1200 \mathrm{~cm}^{-1}$ and is mainly due to water vapour emission. The ozone absorption band occurring between 1000 and $1080 \mathrm{~cm}^{-1}$ is followed by an atmospheric window between 1100 and $1200 \mathrm{~cm}^{-1}$ that contains some $\mathrm{SO}_{2}$ and $\mathrm{N}_{2} \mathrm{O}$ absorption. Above $1200 \mathrm{~cm}^{-1}$ there is water vapour absorption together with features for $\mathrm{N}_{2} \mathrm{O}, \mathrm{CH}_{4}$ and the relatively strong $\mathrm{SO}_{2}$ absorption.

Figure 2 shows the brightness temperature spectra simulated with the reference clear atmosphere and with the addition of a tropospheric (Fig. 2a) or stratospheric (Fig. 2b) plume containing either 10 or $100 \mathrm{DU}$ of $\mathrm{SO}_{2}$. Figure $2 \mathrm{c}$ and Figure $2 \mathrm{~d}$ show the brightness temperature differences between the reference and $\mathrm{SO}_{2}$ enhanced atmospheres. The IASI spectra are sensitive to both the amount of $\mathrm{SO}_{2}$ and the altitude of the plume. The difference in the sensitivity spectra suggests that both plume height and column amount can be retrieved. The effect of both $\mathrm{SO}_{2}$ absorption bands $\left(v_{1}\right.$ and $\left.\nu_{3}\right)$ are attenuated by other atmospheric constituents so that increasing the altitude of the plume (as well as increasing $\mathrm{SO}_{2}$ ) produces an increase in the $\mathrm{SO}_{2}$ signal. Note that the symmetric $v_{1}$ absorption signal, does not change significantly in spectral shape between plumes at different altitudes. This means that this spectral region does not contain information on the plume altitude itself. It is the modulation of the spectral shape of the $v_{3}$ absorption band by the absorption of other gases (such as water vapour) that gives different spectral behaviours for tropospheric and stratospheric plumes. This is the part of the spectra that contains information on the plume altitude. Note that getting the altitude correct is important not just in itself but also in order to get 
(a)

(b)

(c)

(d)

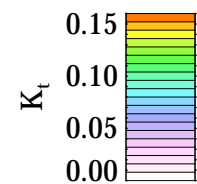

(e)

$$
\begin{array}{r}
0.000 \\
-0.002
\end{array}
$$

o -0.004

羟-0.006

$-0.008$

$-0.010$

(f)

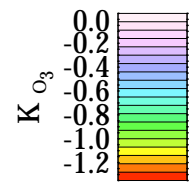

(g)

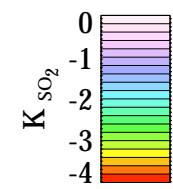

(h)

(i)
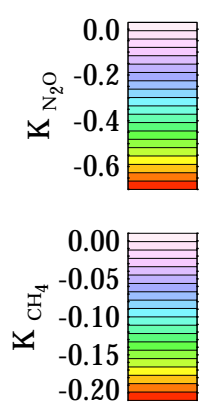
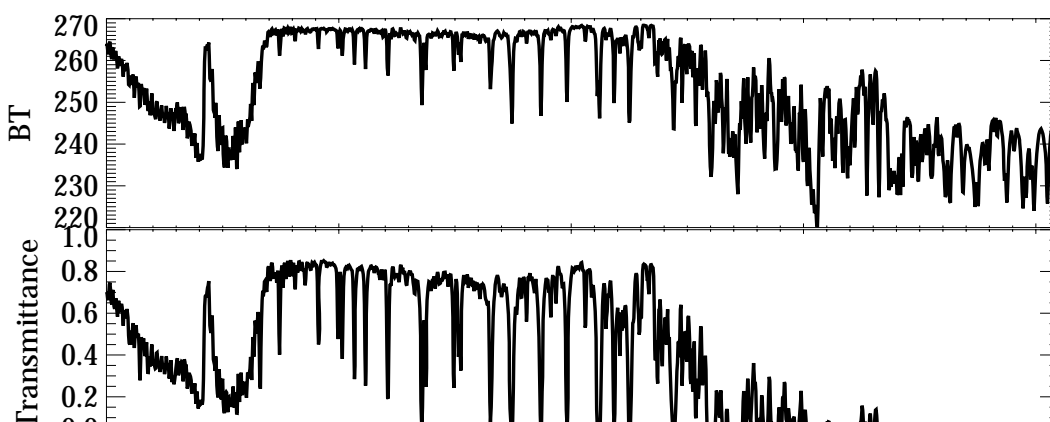

코
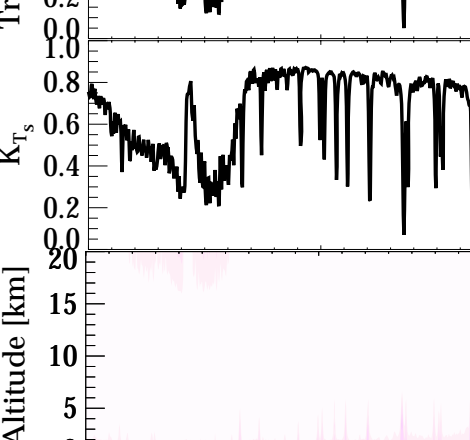

¿ 28

吾 15 E

总 10

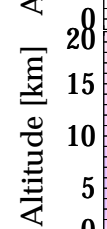

吾 15 E

咅 15 E

吾 15 焉

1000
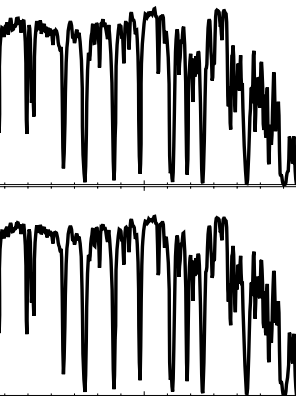

dint
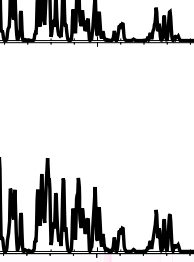


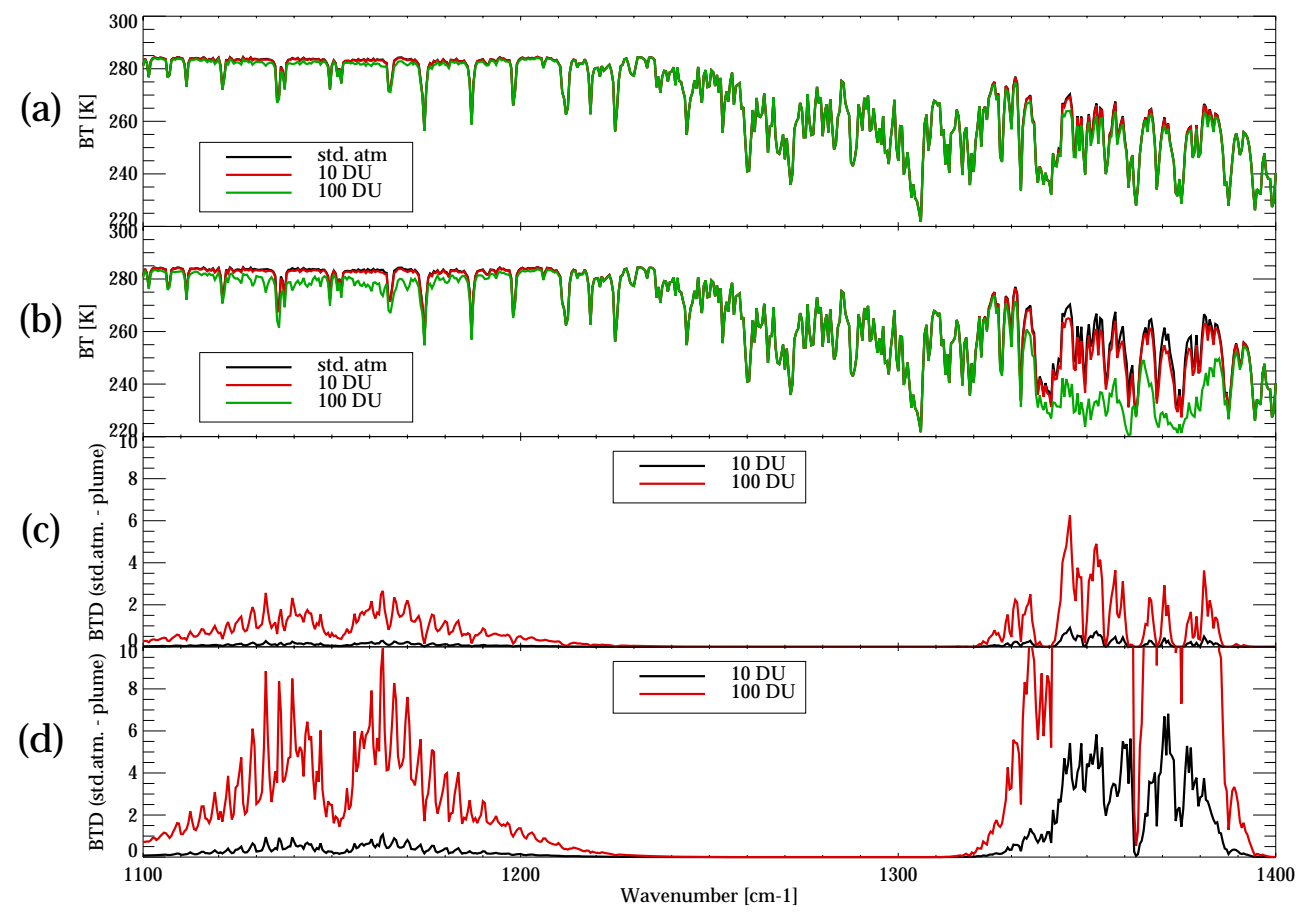

Fig. 2. (a) Simulated IASI spectra brightness temperature spectra for (i) the reference clear atmosphere (black line) (ii) the reference clear atmosphere with the addition of a tropospheric $\mathrm{SO}_{2}$ plume between 1 and $5 \mathrm{~km}$ containing a total column amount of $10 \mathrm{DU}$ (red line) or $100 \mathrm{DU}$ (green line) of $\mathrm{SO}_{2}$; (b) Simulated IASI spectra brightness temperature spectra for (i) the reference clear atmosphere (black line) (ii) the reference clear atmosphere with the addition of a stratospheric $\mathrm{SO}_{2}$ plume between 9 and $14 \mathrm{~km}$ containing a total column amount of $10 \mathrm{DU}$ (red line) or $100 \mathrm{DU}$ (green line) of $\mathrm{SO}_{2}$; (c) Brightness temperature differences $\left(\Delta T_{\mathrm{B}}\right)$ between the the reference clear atmosphere and the reference clear atmosphere enhanced by a tropospheric $\mathrm{SO}_{2}$ plume containing a total column amount of $10 \mathrm{DU}$ (black line) or $100 \mathrm{DU}$ (red line) of $\mathrm{SO}_{2} ;$ (d) Brightness temperature differences $\left(\Delta T_{\mathrm{B}}\right)$ between the reference clear atmosphere and the reference clear atmosphere enhanced by a stratospheric $\mathrm{SO}_{2}$ plume containing a total column amount of $10 \mathrm{DU}$ (black line) or $100 \mathrm{DU}$ (red line) of $\mathrm{SO}_{2}$.

the correct amount of $\mathrm{SO}_{2}$, since the TOA signal depends strongly on plume altitude.

\subsection{Error covariance matrix}

The error covariance matrix $\mathbf{S}_{\epsilon}$ encapsulates the variability between the IASI measured spectra and the radiative transfer calculations for conditions when there is assumed to be negligible $\mathrm{SO}_{2}$ present in the atmosphere. For the Eyjafjallajökull eruption the error covariance matrix for April or May was calculated from the IASI data in the North Atlantic region $\left(45-70^{\circ} \mathrm{N}, 40^{\circ} \mathrm{W}-10^{\circ} \mathrm{E}\right)$ for the same month but the year before (i.e. April or May, 2009). For every IASI spectra $\boldsymbol{y}$, a simulated spectra $\boldsymbol{y}_{\mathrm{S}}$ was calculated using the forward model with corresponding ECMWF data and the $\mathrm{SO}_{2}$ amount fixed to zero. Each element in the error covariance matrix was calculate using

$S_{\epsilon}(i, j)=\left\langle\left[\left(y_{i}-y_{s i}\right)-\left(\overline{y_{i}-y_{s i}}\right)\right]\left[\left(y_{j}-y_{s j}\right)-\left(\overline{y_{j}-y_{s j}}\right)\right]\right\rangle$

where the terms $\overline{y_{i}-y_{s i}}$ and $\overline{y_{j}-y_{s j}}$ are the spectra of average differences between measurements and simulations. This is the bias term $(\boldsymbol{c})$ that is considered inside the cost function (Eq. 2) during the retrieval.
The error covariance matrix computed in this way will include the variability of every atmospheric constituent that is not represented by the forward model (e.g. cloud), the errors in ECMWF profiles, the errors in spectroscopy of minor gases as well the instrumental error. The error covariance matrix will not include any variability due to $\mathrm{SO}_{2}$ because it has been deliberately calculated from IASI observations that are not affected by a volcanic plume or strong industrial pollution.

Because (i) the computation of a covariance matrix based on a large ensemble of IASI pixels with the same climatology (as the same month the year before) requires long computation time (longer that the retrieval itself if applied to a sporadic volcanic eruption) and (ii) the impossibility of selecting IASI pixels that are not affected by $\mathrm{SO}_{2}$ in some regions where there is a particularly active volcano degassing, a global error covariance matrix has been computed in the same manner as the 'local' one. The global error covariance was based on four days (one every season) of IASI data during 2009 (more than 5 million pixels). This global error covariance matrix can be applied anywhere but will give higher errors in $\mathrm{SO}_{2}$ because more variability is included in the $\mathbf{S}_{\epsilon}$. 


\subsection{Effect of a cloud or ash layer}

The influence of particulates on the retrieved $\mathrm{SO}_{2}$ plume properties has been investigated by including a layer of scattering and absorbing material in the forward model in a similar approach to that of the Oxford-RAL Retrieval of Aerosol and Cloud scheme (Thomas et al., 2009; Poulsen et al., 2012). The particulate layer can represent an aerosol layer (ash, desert dust or maritime) or a water cloud layer. Other types of layer composition can be easily implemented using the appropriate optical properties. The atmosphere above and below the layer is considered to be composed purely of gas.

The optical properties (spectral extinction coefficient, single scattering albedo and phase function) of the scattering layer are calculated using Mie theory and used to build lookup-tables (LUTs) of emissivity $(\epsilon)$, reflectance $(\mathcal{R})$ and transmittance $(\mathcal{T})$ using the DIscrete Ordinates Radiative Transfer (DISORT, Stamnes et al., 1988) code. The LUTs are functions of the instrument channel, the geometry of observations, the optical depth of the layer and the effective radius of the particle.

The TOA radiance $L_{\bullet}^{\uparrow}$ for an atmosphere that includes a scattering layer at level $l$ is then given by

$L_{\bullet}^{\uparrow}=\epsilon B\left(T_{1}\right) \mathcal{T}_{\mathrm{al}}+L_{\mathrm{al}}^{\uparrow}+L_{\mathrm{al}}^{\downarrow} \mathcal{R} \mathcal{T}_{\mathrm{al}}+L_{\mathrm{bl}}^{\uparrow} \mathcal{T} \mathcal{T}_{\mathrm{al}}$

where $B\left(T_{l}\right)$ is the Planck radiance at the layer temperature $T_{1}, \mathcal{T}_{\text {al }}$ is the transmittance from the layer to space, $L_{\text {al }}^{\uparrow}$ is the up-welling radiance at the TOA from the atmosphere above the layer, $L_{\mathrm{al}}^{\downarrow}$ is the down-welling radiance at the top of the layer and $L_{\mathrm{bl}}^{\uparrow}$ is the up-welling radiance at the bottom of the layer. The four terms on the right-hand-side of Eq. (9) can be understood as (i) the radiance emitted by the scattering layer, (ii) the radiation emitted to the TOA by the atmosphere above the scattering layer, (iii) the down-welling radiation at the top of the scattering layer that is reflected to the TOA and (iv) the up-welling radiation at the bottom of the layer that is transmitted to the TOA. This last term must account for contributions from the atmosphere below the scattering layer and the surface, i.e.

$L_{\mathrm{bl}}^{\uparrow}=L_{\mathrm{bl}}^{\uparrow(\mathrm{atm})}+\epsilon_{\mathrm{s}} B\left(T_{\mathrm{s}}\right) \mathcal{T}_{\mathrm{bl}}$

where $L_{\mathrm{bl}}^{\uparrow(\mathrm{atm})}$ is the atmospheric component of the upwelling radiance below the scattering layer, $B\left(T_{\mathrm{s}}\right)$ is the Planck radiance from the surface at temperature $T_{\mathrm{s}}, \mathcal{T}_{\mathrm{bl}}$ is the transmittance from the surface to the layer and, $\epsilon_{\mathrm{s}}$ is the emissivity of the surface. The terms $L_{\mathrm{al}}^{\uparrow}, L_{\mathrm{al}}^{\downarrow}, \mathcal{T}_{\mathrm{al}}$ and $L_{\mathrm{bl}}^{\uparrow}$ are independent of the scattering layer and are efficiently calculated using the fast forward model.

\section{Error analysis}

The estimated error covariance of the retrieved state is obtained from (Rodgers, 2000)

$\mathbf{S}_{\hat{\boldsymbol{x}}}=\left(\mathbf{K}^{\mathrm{T}} \mathbf{S}_{\epsilon}^{-1} \mathbf{K}+\mathbf{S}_{\mathrm{a}}^{-1}\right)^{-1}$,

where the weighting function $\mathbf{K}$ is computed at the solution $\hat{\boldsymbol{x}}$. The square root of the diagonal elements of $\mathbf{S}_{\hat{\boldsymbol{x}}}$ are an estimate of the errors in $\hat{\boldsymbol{x}}$. The averaging kernel $\mathbf{A}$ represents the sensitivity of the retrieved state to the true state and can be found from (Rodgers, 2000)

$\mathbf{A}=\mathbf{S}_{\hat{x}}\left(\mathbf{S}_{\hat{x}}-\mathbf{S}_{\mathrm{a}}^{-1}\right)=\mathbf{I}-\mathbf{S}_{\hat{x}} \mathbf{S}_{\mathrm{a}}^{-1}$.

The sum of the diagonal elements (the trace) of $\mathbf{A}$ gives the degrees-of-freedom (DF) of the retrieval. The DF can be interpreted as the number of parameters (of the state vector) that can be independently retrieved.

Retrievals were performed on simulated data to assess the sensitivity of the retrieved parameters to perturbations in the state. The analysis was performed with synthetic spectra produced with an $\mathrm{SO}_{2}$ plume added to the reference clear atmosphere. In the simulations the $\mathrm{SO}_{2}$ column amount varied between 0.1 and $100 \mathrm{DU}$ and plume altitude lay between 100 and $1000 \mathrm{mb}$ (16 and $0 \mathrm{~km})$. Two surface temperature values were considered: firstly, the surface temperature was set equal to the temperature of the lowest atmospheric layer (this is the worst case for a nadir retrieval in the thermal infrared); secondly, the surface temperature was set to the lowest atmospheric layer plus $10 \mathrm{~K}$. Hence the retrieval was tested for zero and some thermal contrast between the lowest atmospheric layer and the surface. The retrievals used a priori values of $0.5 \pm 100 \mathrm{DU}$ for $\mathrm{SO}_{2}$ column amount and $400 \pm 1000 \mathrm{mb}$ for plume altitude. A priori surface temperature was set to the temperature of the lowest atmospheric layer with an uncertainty of $20 \mathrm{~K}$.

The error covariance matrices considered were the "local" covariance matrix, i.e. the one computed for April above the Icelandic plume region, and the "global" covariance matrix. The local error covariance matrix for May gives results that are similar to using the covariance matrix for April so are not reported here.

Figure 3 shows the errors in the retrieved state and the degrees-of-freedom in the retrieval. The error in the $\mathrm{SO}_{2}$ column amount strongly depends on plume altitude, increasing when the plume height decreases, so having a maximum uncertainty close to the surface. The minimum error, less than $1 \mathrm{DU}$, occurs at for altitudes greater than about $8 \mathrm{~km}$. The error on $\mathrm{SO}_{2}$ amount also slightly increases with increasing $\mathrm{SO}_{2}$ column amount. The lowest percentage errors occur at high altitudes and large amounts of $\mathrm{SO}_{2}$. The retrieval performs poorest close to the surface when the $\mathrm{SO}_{2}$ column amount is less than $2 \mathrm{DU}$.

The retrieved altitude error is typically on the order of $1-2 \mathrm{~km}$ for plumes containing $10 \mathrm{DU}$ or more of $\mathrm{SO}_{2}$. As 


\section{Local covariance No thermal contrast}
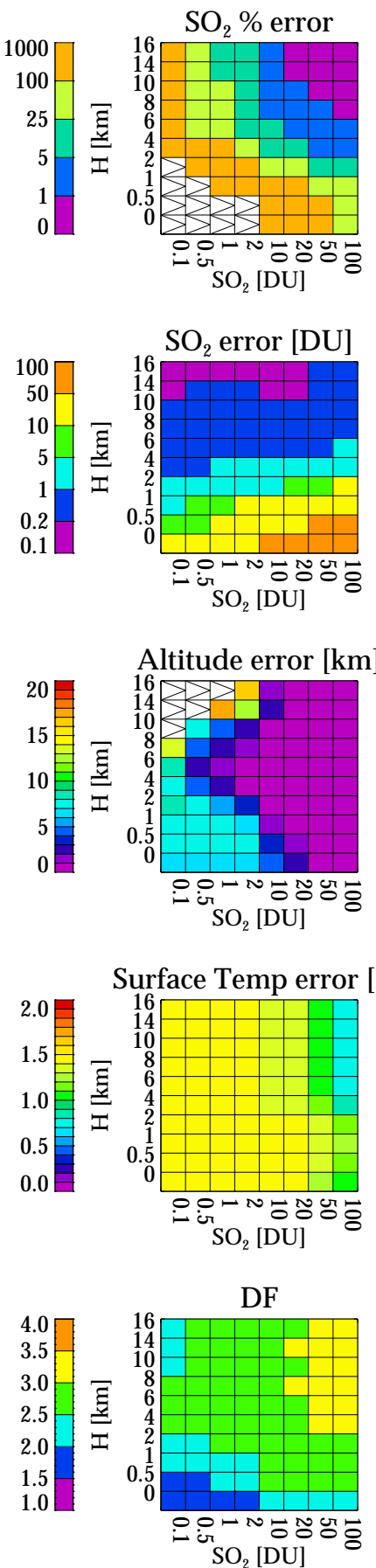

\section{Global covariance} No thermal contrast
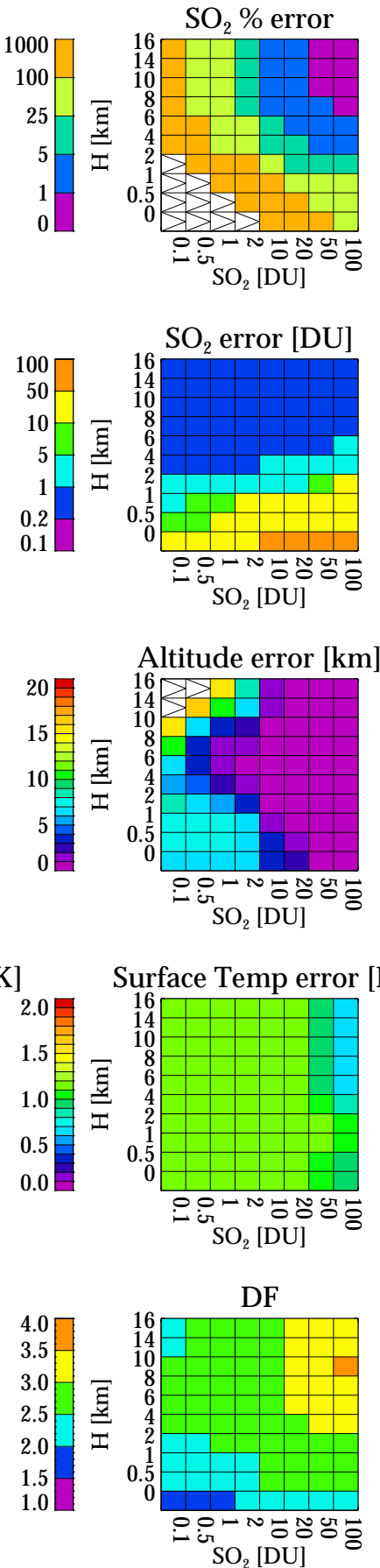

Local covariance With thermal contrast.
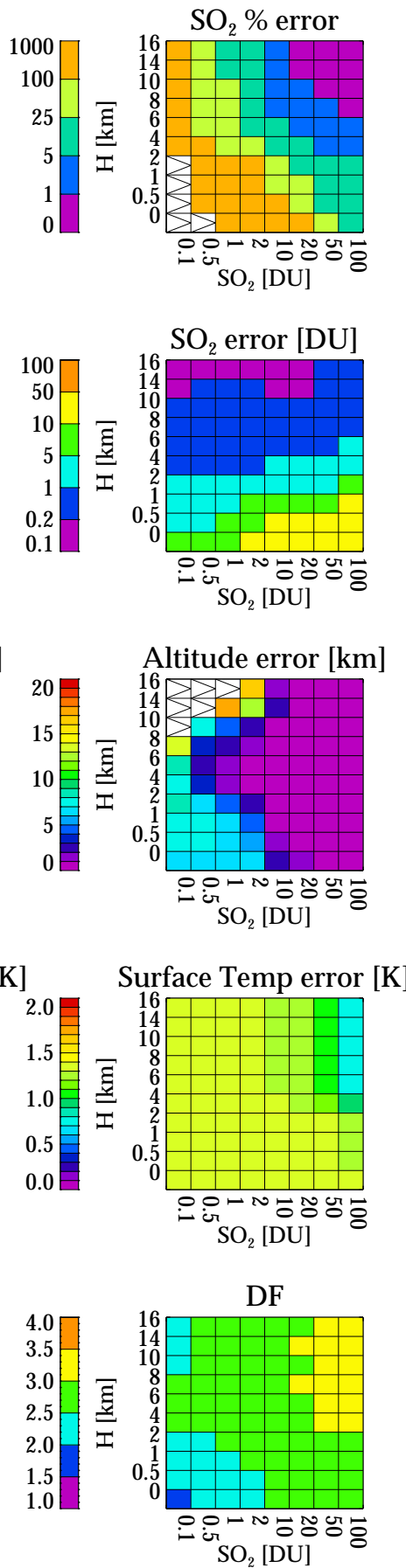

Fig. 3. The error in the retrieved state and the degrees-of-freedom in the retrieval are shown as a function of $\mathrm{SO}_{2}$ column amount (on the ordinate) and the altitude of the plume (on the abscissa). From top to bottom the rows show the percentage error in $\mathrm{SO}_{2}$ column amount, the absolute errors in the $\mathrm{SO}_{2}$ column amount, plume altitude, and surface temperature and the last row shows the degree-of-freedom in the retrieval. The columns denote the values obtained using (i) the local error covariance matrix for April and no thermal contrast between surface and atmosphere, (ii) the global error covariance matrix and no thermal contrast, and (iii) the local covariance matrix and $10 \mathrm{~K}$ of thermal contrast between surface and atmosphere. Values higher than the colour bar are shown by a white box containing the symbol " $>$ ". 
Local covariance No thermal contrast
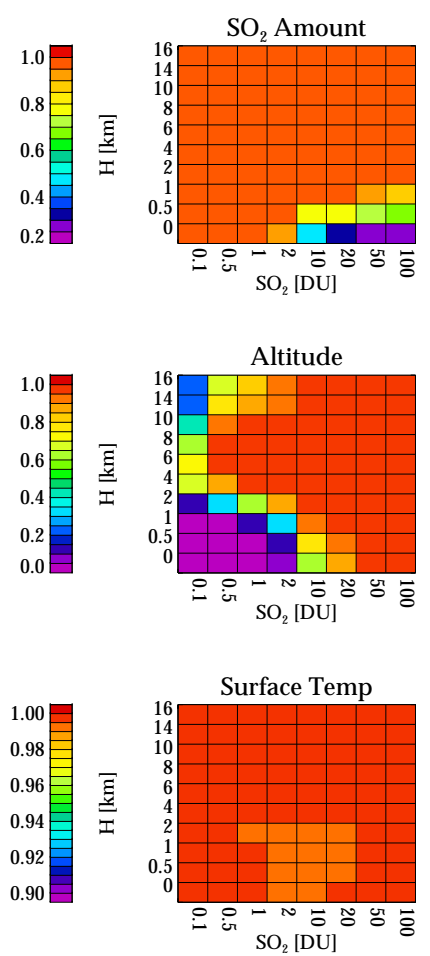

Global covariance No thermal contrast

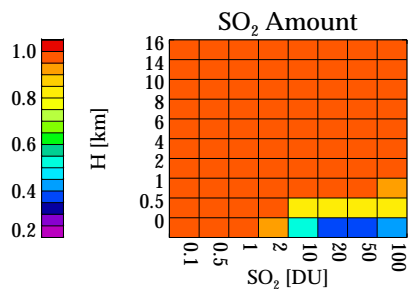

Altitude
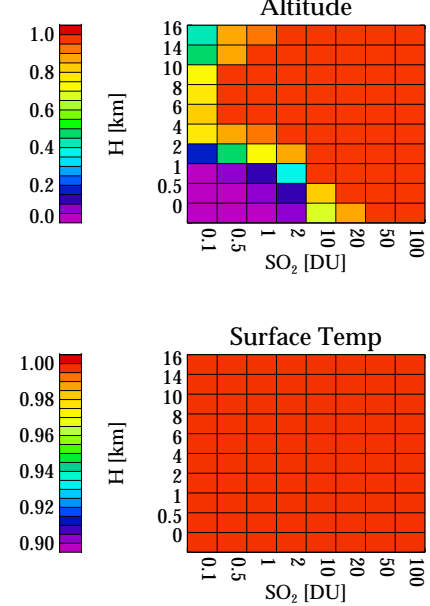

Local covariance With thermal contrast.
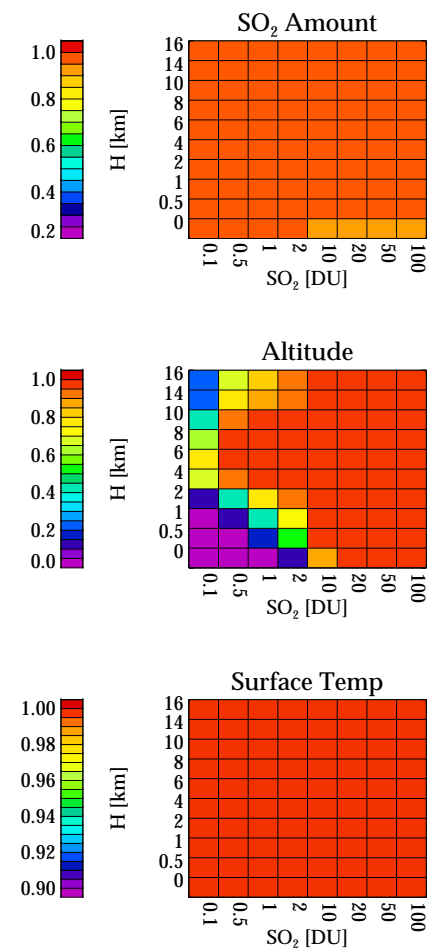

Fig. 4. Values of the averaging kernel (for $\mathrm{SO}_{2}$ amount, altitude and surface temperature) as a function of $\mathrm{SO}_{2}$ amount and altitude used in the simulations. The first column presents the values obtained computing the averaging kernel with the local error covariance matrix for April and no thermal contrast between surface and atmosphere. The second column presents the values using the global covariance matrix and no thermal contrast. The third column is obtained with the local covariance matrix and $10 \mathrm{~K}$ of thermal contrast between surface and atmosphere.

the plume thins the information on height is reduced so that the reported altitude tends to the a priori $(400 \mathrm{mb})$ and the reported error is the a priori error. When this happens the $\mathrm{SO}_{2}$ amount for conditions close to the surface are underestimated. Note that retrievals of low amount of $\mathrm{SO}_{2}$ when the plume is close to the surface can produce negative values of $\mathrm{SO}_{2}$. Conversely the error in surface temperature is always below $1.5 \mathrm{~K}$ except where the plume is thick and the error gets even smaller.

The conditions, where the DF is three or more, correspond to cases where it is possible to retrieve all three parameters in the state vector $\left(\mathrm{SO}_{2}\right.$ amount, altitude and surface temperature). These conditions also correspond to smaller errors in the plume altitude.

The general behaviour of the estimated errors is the same for both the global and local measurement covariances. The main difference being that the errors determined using the global covariance matrix are slightly higher for all the state vector elements. Increasing the thermal contrast between the surface and the atmosphere reduces the region of poor retrievals.
Note that when the plume is near the tropopause there can often exist two altitudes at the same temperature (either side of the tropopause) with very similar transmittances to the TOA. This results in a large error in retrieved plume altitude but does not significantly affect the retrieved $\mathrm{SO}_{2}$ column amount. In this situation the volcanic plume is well above the tropospheric boundary layer, which contains the majority of water vapour (which is the main cause of extinction in the $v_{3}$ band), and so the $\mathrm{SO}_{2}$ signal does not varying between these layers with the same temperature. As a consequence, these layers are indistinguishable and the retrieved altitude depends strongly on the a priori and first guess. Still, the amount of retrieved $\mathrm{SO}_{2}$ is reliable.

Figure 4 shows the diagonal value of the averaging kernel, $\left(\mathrm{SO}_{2}\right.$ column amount, plume altitude and surface temperature), calculated for the same range of conditions as shown in Fig. 3. An ideal value of one indicates that the retrieval is sensitive to a change in the true state. Values much less that one imply the state vector element is poorly observed and information is coming from the a priori. All three state vectors are well retrieved over much of the domain. The regions 
where the values are less than one, i.e. thin plumes or plumes near the surface, reinforce the conclusions drawn from Fig. 3.

An error not included in this analysis is the error in the $\mathrm{SO}_{2}$ line strength caused by error in the temperature profile. A test was conducted (for all $\mathrm{SO}_{2}$ amounts and altitudes in Fig. 3) where $1 \mathrm{~K}$ of was added to ECMWF temperature profile at every level. The resulting error was a few percent of the total error reported in Fig. 3. Note that errors in the line strength of other gases caused by error in the temperature profile are accounted for using the generalized $\mathbf{S}_{\epsilon}$.

\subsection{Influence of ash and cloud layer}

The influence of an ash or cloud layer on simulated IASI spectra are shown in Fig. 5. The spectra for a thick water cloud and an ash layer suppresses the $\mathrm{SO}_{2}$ signal in the $v_{1}$ band, but in the $v_{3}$ band ash has a smaller impact than cloud. To investigate this further IASI spectra were simulated for different ash optical depths (from 0.2 to 20, at the reference wavelength of 550nm) and an effective radius of $2 \mu \mathrm{m}$. Ash refractive indices were from Grainger et al. (2012). The effective radius was chosen to be typical of the values retrieved $(1-3 \mu \mathrm{m})$ for the Eyjafjallajökull eruption from AATSR and SEVIRI measurements (STFC, 2011; Grainger et al., 2012). In addition IASI spectra were simulated for an atmosphere containing water cloud with an optical depth, at $550 \mathrm{~nm}$, in the range 1-30 and an effective radius of $15 \mu \mathrm{m}$. In the simulations the altitude of the ash or cloud layer was varied between 0 and $11 \mathrm{~km}(1000$ and $200 \mathrm{mb})$. All the atmospheres used to calculate the synthetic spectra included an $\mathrm{SO}_{2}$ plume with a column amount of $50 \mathrm{DU}$ and a maximum concentration at $400 \mathrm{mb}(6.4 \mathrm{~km})$. There was no thermal contrast between the surface and the bottom atmospheric layer (both were set to $270 \mathrm{~K}$ ).

Figure 6 shows the results when the $\mathrm{SO}_{2}$ retrieval was applied to the simulated spectra. The presence of ash with optical depth greater than 1 within the $\mathrm{SO}_{2}$ plume (i.e. within the spread of the assumed Gaussian profile) can significantly affect the retrieved amount. The $\mathrm{SO}_{2}$ column amount is underestimated by about $50 \%$ for an ash layer with an optical depth of 2 and is masked completely when the ash optical depth is greater than 5 . These conditions also produce a cost function value higher than two and consequently can be identified a posteriori. A possible option, for future work, would be to perform both $\mathrm{SO}_{2}$ and ash retrievals simultaneously for these scenes.

The presence of cloud below the $\mathrm{SO}_{2}$ plume does not significantly affect the retrieval because the cloud signal is included in the variability considered in the error covariance matrix. As soon as the cloud layers reaches layers containing $\mathrm{SO}_{2}$ the cloud attenuates the spectral signal of the underlying $\mathrm{SO}_{2}$ so the column amount of $\mathrm{SO}_{2}$ is underestimated. Very low column amounts of $\mathrm{SO}_{2}$ are retrieved when the cloud is above the volcanic plume. These conditions are distinguishable by large values of the cost function.
To conclude, the retrieval method is mainly based on fitting the $\mathrm{SO}_{2}$ spectral shape. Spectral signatures described by the covariance matrix (due to cloud presence, surface temperature, imperfectly modelled instrumental effects etc.) should not influence the resulting $\mathrm{SO}_{2}$ retrieval. Atmospheric effects which modify the $\mathrm{SO}_{2}$ spectral signature (e.g. cloud above the plume) will affect the retrieval. The presence of cloud and ash within the plume reduces the $\mathrm{SO}_{2}$ spectral signature and produces an underestimation of the total column amount of $\mathrm{SO}_{2}$. This behaviour is the opposite of what happens in $\mathrm{SO}_{2}$ retrievals that are based on $\mathrm{SO}_{2}$ absorption (e.g. Corradini et al., 2008). In these schemes, the presence of ash decreases the radiance measured in the $\mathrm{SO}_{2}$ channel and, if not corrected, produces an overestimation of $\mathrm{SO}_{2}$ column amount (Kearney and Watson, 2009; Corradini et al., 2010).

\section{Case study: Eyjafjallajökull eruption during April and May 2010}

Eyjafjallajökull is a stratovolcano, located close to Iceland's southern coast at $63^{\circ} 38^{\prime} \mathrm{N}, 19^{\circ} 36^{\prime} \mathrm{W}$ with an elevation of $1666 \mathrm{~m}$. The volcano entered a precursor eruptive phase on 20 March 2010 that included lava flows but no significant ash and $\mathrm{SO}_{2}$ emission. Following earthquake activity an explosive eruption began on the 14 April 2010. The explosive part of the eruption can be divided into three phases (Zehner, 2012; Stevenson et al., 2012; Petersen et al., 2012):

Phase I: 14-18 April. A phreatomagmatic eruption where ice and water from the ice cup above the caldera were directly in contact with the fresh magma in the vent. This produced a faster cooling of the ejected magma and a large amount of ash and steam. During this period the injection altitude of the plume is estimated at between 2 and $10 \mathrm{~km}$ (Marzano et al., 2011; Stohl et al., 2011) and the wind conditions transported the ash plume in a SE direction, towards Europe (Petersen et al., 2012). This was the most powerful phase of the eruption with the highest mass discharge rate (Stevenson et al., 2012). The majority of the tephra deposited in Europe was produced in this phase (Stevenson et al., 2012).

Phase II: 18 April-4 May. From the evening of 18 April water and ice from the glacier were no longer inside the vent so that the eruption became purely magmatic with effusive phases (Petersen et al., 2012). The intensity of the eruption was an order of magnitude lower than Phase I, with reduced amounts of ash injected into the atmosphere. The altitude of the eruption column was between 2 and 5 km (Zehner, 2012; Stohl et al., 2011).

Phase III: 5 May-24 May. Between 3-5 May an increase in seismic activity was followed by a more intense explosive eruptions. The discharge rate increased and was highly variable (Stevenson et al., 2012). Ash production increased and the eruption column altitude was between 4 and $10 \mathrm{~km}$ (Stohl et al., 2011). Ash was transported over Europe and the Atlantic Ocean.

The various phases of the eruption were observed from satellite (Thomas and Prata, 2011; Francis et al., 2012; Rix et al., 2012), aircraft (Schumann et al., 2011; Marenco et al., 


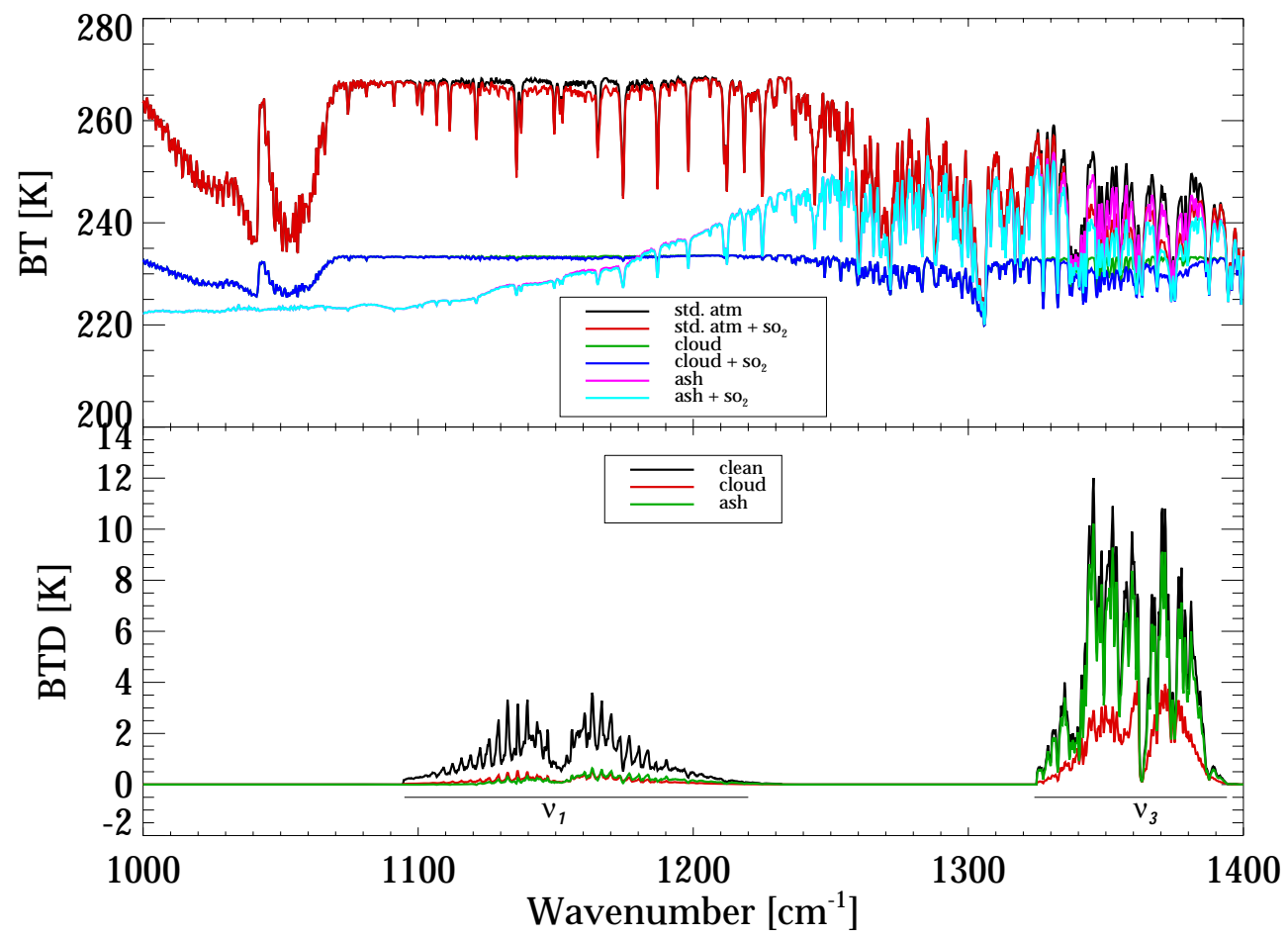

Fig. 5. The top plot shows simulated IASI spectra for (a) the clear reference atmosphere (black line), (b) the clear reference atmosphere with the addition of $\mathrm{SO}_{2}$ plume (red), (c) the clear reference atmosphere with the addition of a water cloud (green), the clear reference atmosphere with the addition of a water cloud and $\mathrm{SO}_{2}$ plume (blue), the clear reference atmosphere with the addition of an ash layer (pink); the clear reference atmosphere with the addition of an ash layer and $\mathrm{SO}_{2}$ plume (cyan). The water cloud had an effective radius of $20 \mu \mathrm{m}$, an optical depth of 10 at $550 \mathrm{~nm}$ and an altitude of $400 \mathrm{mb}$. The ash layer had an effective radius of $2 \mu \mathrm{m}$, an optical depth of 3 at $550 \mathrm{~nm}$, and an altitude of $400 \mathrm{mb}$. The $\mathrm{SO}_{2}$ plume had a Gaussian profile with a column amount of $50 \mathrm{DU}$, a maximum concentration at $400 \mathrm{mb}(\sim 6.4 \mathrm{~km})$ and a vertical spread of $100 \mathrm{mb}$. The bottom plot shows the brightness temperature difference between IASI spectra simulated for clear, cloud and ash laden with and without an $\mathrm{SO}_{2}$ plume.

2011; Rauthe-Schöch et al., 2012) and the ground (Harrison et al., 2010; Mona et al., 2012). The volcanic plumes from the eruption of Eyjafjallajökull resulted in the cancellation of 107000 flights over Europe (or $48 \%$ of total air traffic) affecting roughly 10 million passengers (European Commission, 2010). The airline industry lost an estimated 153 million pounds a day during the period when European airspace was closed (Mazzocchi et al., 2010).

Rather than run the retrieval on every IASI pixel the method of Walker et al. (2011) was used to flag pixels indicating enhanced levels of $\mathrm{SO}_{2}$. The sensitivity of this detection method can be tuned by setting a threshold on the probability that random noise or background atmospheric variability could generate a false detection. In this analysis the threshold is set to 1 in 10000 . All flagged IASI pixels were processed to give a column amount of $\mathrm{SO}_{2}$ in DU $\left(1 \mathrm{DU}=0.0285 \mathrm{~g} \mathrm{~m}^{-2}\right)$. The retrieved values were further filtered using basic quality control criteria: the retrieval had to converge, $A>0, p_{\mathrm{SO}_{2}}>0$ and $J<10$. Figs. 7-9 show the development of the $\mathrm{SO}_{2}$ plume for each half day in April and May 2010.
The first IASI detection of the Eyjafjallajökull eruption was on the evening of 14 April (Walker et al., 2012). The images show that the first plume arrives over northern Europe on 15th April and spreads over Scandinavia and centraleastern Europe over the following three days. This $\mathrm{SO}_{2}$ plume is 'connected' with the volcano location only in the first two images (the afternoon of the 14th and morning of the 15 th). The plume is then transported according to the meteorological conditions. The fact that there is no $\mathrm{SO}_{2}$ detectable close to the volcano could be because the volcano is not emitting or because interaction with water depletes the $\mathrm{SO}_{2}$ at the source.

In the morning image on the 18th April, there is a new $\mathrm{SO}_{2}$ injection into the atmosphere. This corresponds to the shift to a magmatic eruption (Phase II). In this phase $\mathrm{SO}_{2}$ is not depleted by interaction with water in the caldera. $\mathrm{An} \mathrm{SO}_{2}$ plume can be seen close to the volcano in nearly all the Phase II images between 18th April and 4th May.

Phase III starts during the morning of the 4th May with a strong increase in the the $\mathrm{SO}_{2}$ emitted. Between the 4th and the 8th May the plume overpasses the western part of Europe, in particular the UK, Ireland, France and Spain. 

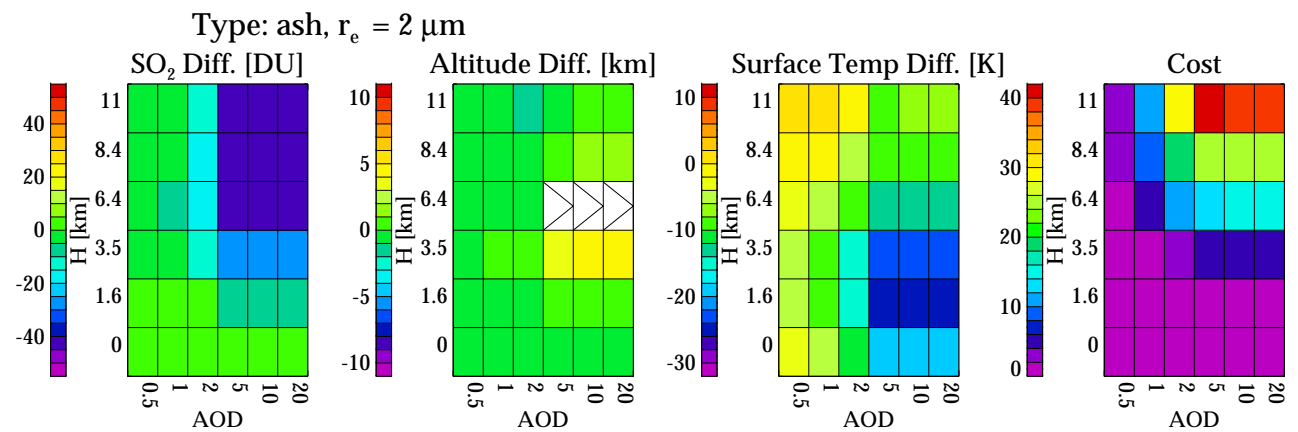

Type: water cloud, $\mathrm{r}_{\mathrm{e}}=20 \mu \mathrm{m}$
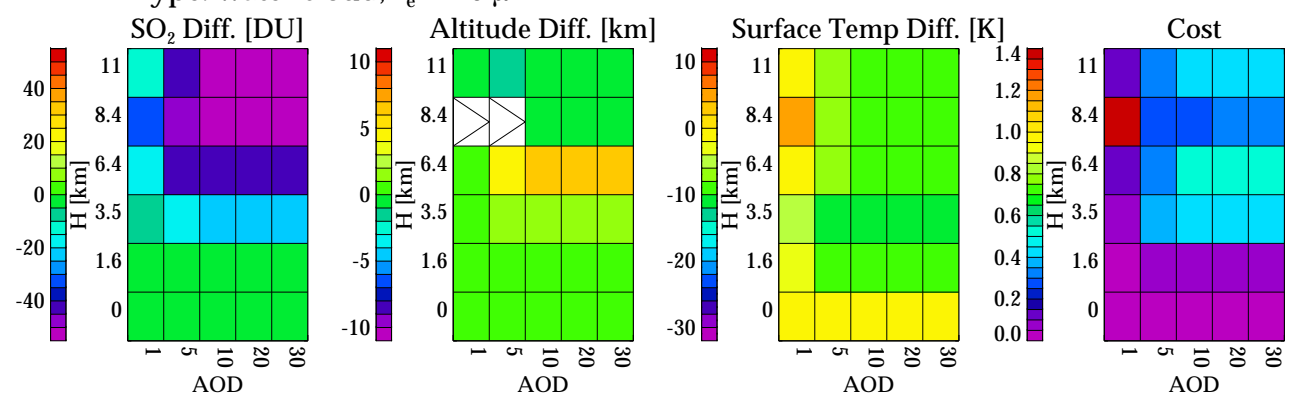

Fig. 6. Difference between the retrieved value and known value for $\mathrm{SO}_{2}$ column amount (first column), altitude (second column), surface temperature (third column). The fourth column shows the value of the cost function. The synthetic IASI data used in the retrievals were based on the reference clear atmosphere containing a $\mathrm{SO}_{2}$ column amount of $50 \mathrm{DU}$, normally distributed about $400 \mathrm{mb}$. The surface temperature was taken as $270 \mathrm{~K}$. The results are shown for top row the presence of an ash layer, the bottom row the presence of a cloud layer. The optical depth and altitude of the ash or cloud layer are a function of the $x$ and $y$ axes respectively.

Unfortunately a missing orbit in the IASI dataset, towards the western side of the region shown, meant a relatively large number of missing values had to be filled. Hence the relatively large amount of $\mathrm{SO}_{2}$ seen on the morning of the 8th May in Figure 9 has to be treated cautiously. On the 9th May the $\mathrm{SO}_{2}$ plume is located over the Atlantic (reaching the coast of Greenland). On the 10th, a filament of the plume passes over Southern Europe, starting over Spain and spreading to the east/north-east. On the morning of the 11th, a fresh plume passes over Ireland, moving towards mainland Europe. At the same time, an older and more dilute plume travels north-east (reaching Scandinavia on 12 May). A new $\mathrm{SO}_{2}$ plume from the volcano is again transported over Europe on 14 May, 16 and 17 May.

In order to compute the total mass of $\mathrm{SO}_{2}$, the accepted data were interpolated onto a $0.125^{\circ}$ grid for each half day in April and May 2010. Finally any missing values within the plume were linearly interpolated from neighbouring grid points. The total mass of $\mathrm{SO}_{2}$ in the atmospheric plume was then found multiplying each grid value by the grid square area. Figure 10 shows the total $\mathrm{SO}_{2}$ mass obtained considering the plume pixels (with latitude between $30-80^{\circ} \mathrm{N}$ and longitude between $50^{\circ} \mathrm{W}$ and $40^{\circ} \mathrm{E}$ ) that have passed quality control criteria (the cost function was less than ten). The error-bars reported are the sum of the error for each grid square value, this assumes a worst case scenario of fully correlated error. The IASI measurements show the reported phases of the eruption. There is small peak in $\mathrm{SO}_{2}$ in Phase I followed by very little $\mathrm{SO}_{2}(<0.1 \mathrm{Tg})$ in Phase II. There is a dramatic increase in Phase III with the total mass of $\mathrm{SO}_{2}$ going from $0.01 \mathrm{Tg}$ on the morning of the 4 th to $0.18 \mathrm{Tg}$ measured on the afternoon of 7 May (the peak of $0.2 \mathrm{Tg}$ on the 8th have to be considered cautiously becouse, due to a missing orbit in IASI dataset, the interpolation procedure extrapolate the $\mathrm{SO} 2$ amount from the values of neighbouring orbits). A secondary maxima occurs around the 16th.

Also shown in Fig. 10 are measurements by GOME-2, OMI and AIRS instruments averaged for the same region. The IASI estimates of total mass $\mathrm{SO}_{2}$ are generally consistent with the OMI and AIRS measurements during Phase II but are higher for the majority of Phase III. To further understand these difference the IASI data were compared with the OMI $\mathrm{SO}_{2}$ plume images (from Thomas and Prata, 2011, and from the IAVCEI Remote Sensing Commission web page). Taking into consideration the time differences between MetOp and A-train measurements, it seems that OMI and IASI give consistent $\mathrm{SO}_{2}$ amounts for the disperse plume but show significant differences for the younger part of the plume, closer to the volcano. An obvious factor that might affect the $\mathrm{SO}_{2}$ retrievals in this area is the presence of volcanic ash. However this does not explain high IASI values as the analysis of the retrieval method showed that for thick ash 


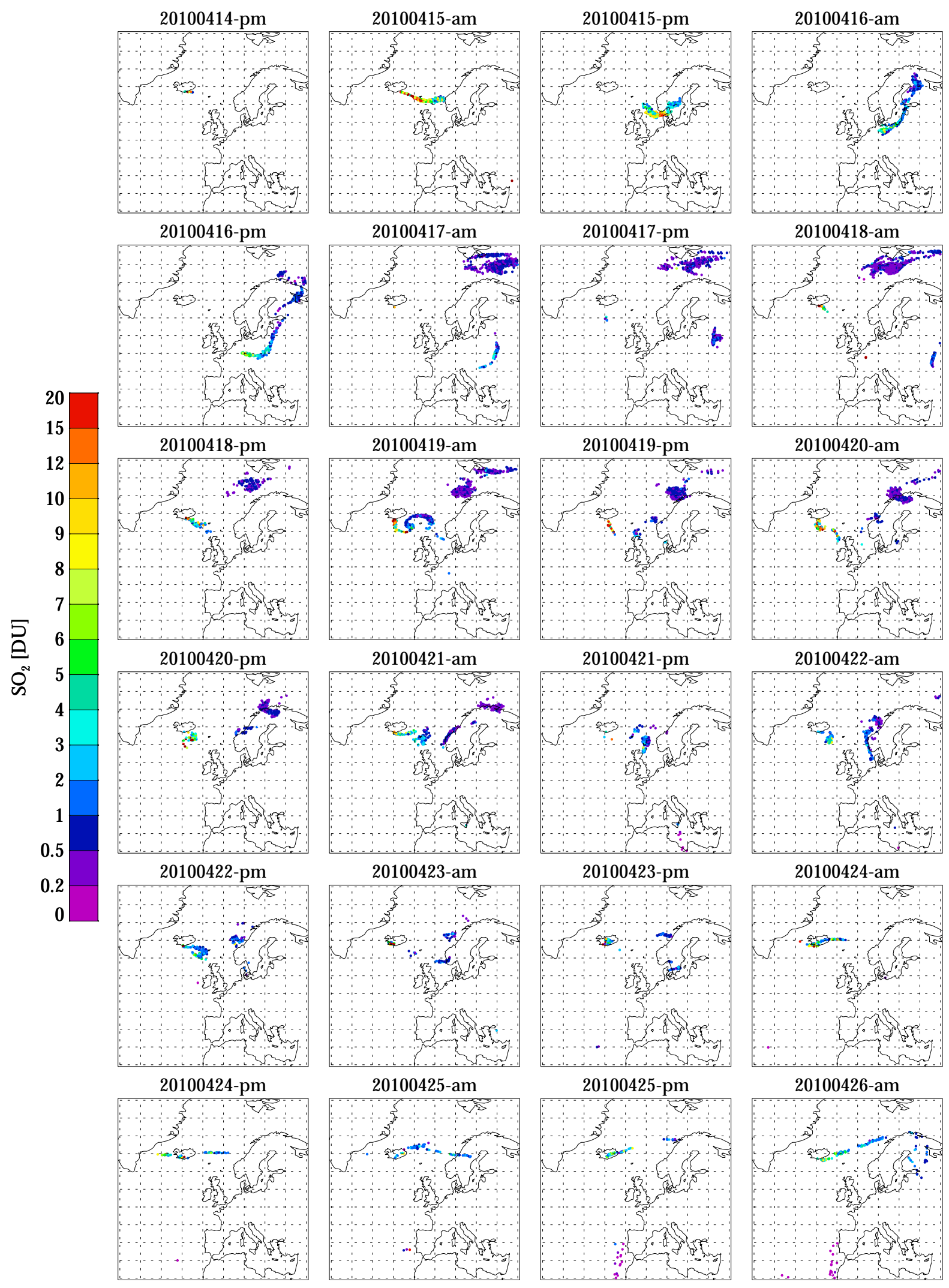

Fig. 7. IASI $\mathrm{SO}_{2}$ column amount, divided into morning and afternoon orbits, for the period from 14 to 26 April 2010. 


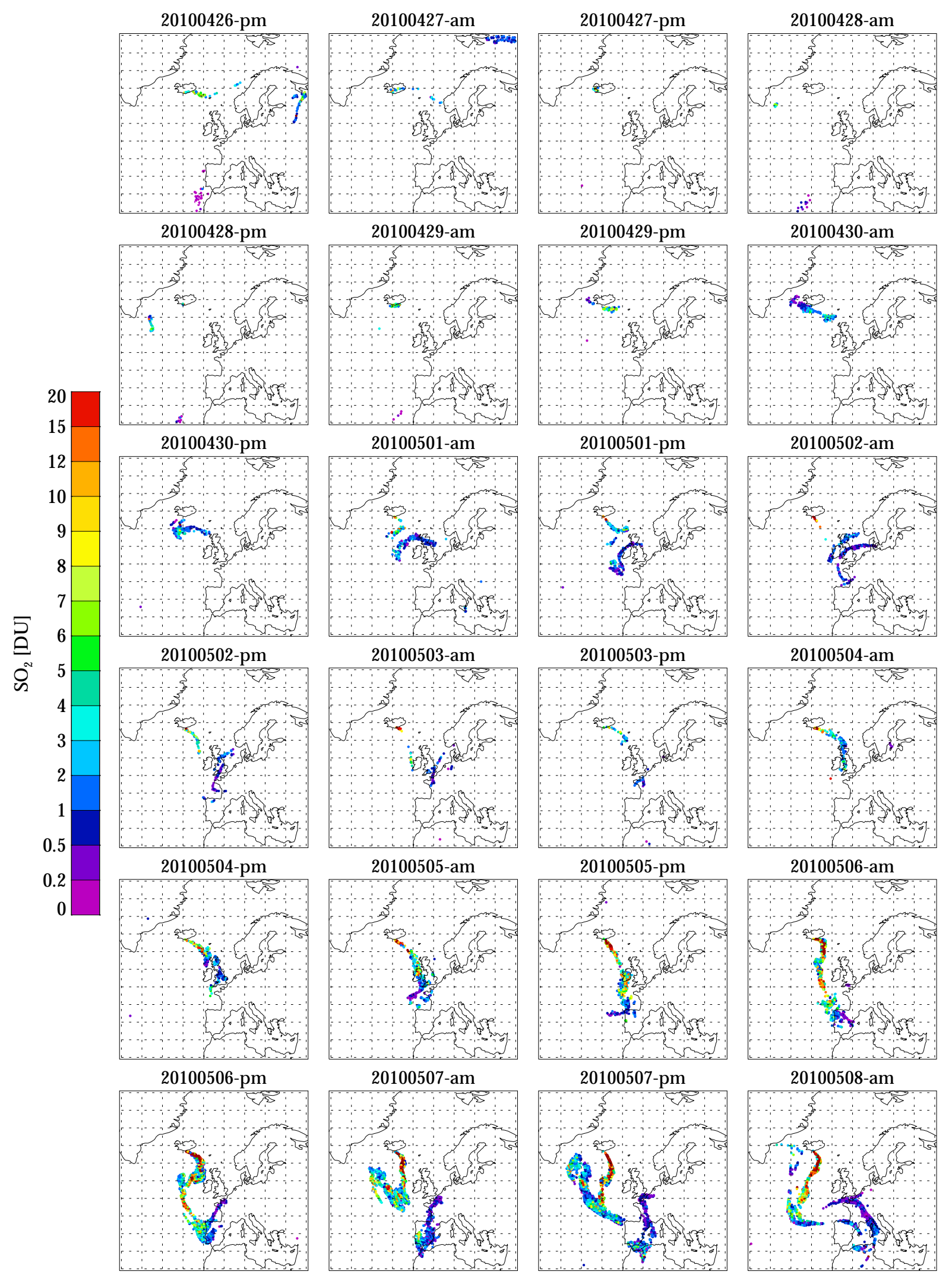

Fig. 8. IASI $\mathrm{SO}_{2}$ column amount, divided into morning and afternoon orbits, for the period from 26 April 2010 to 8 May 2010 . 


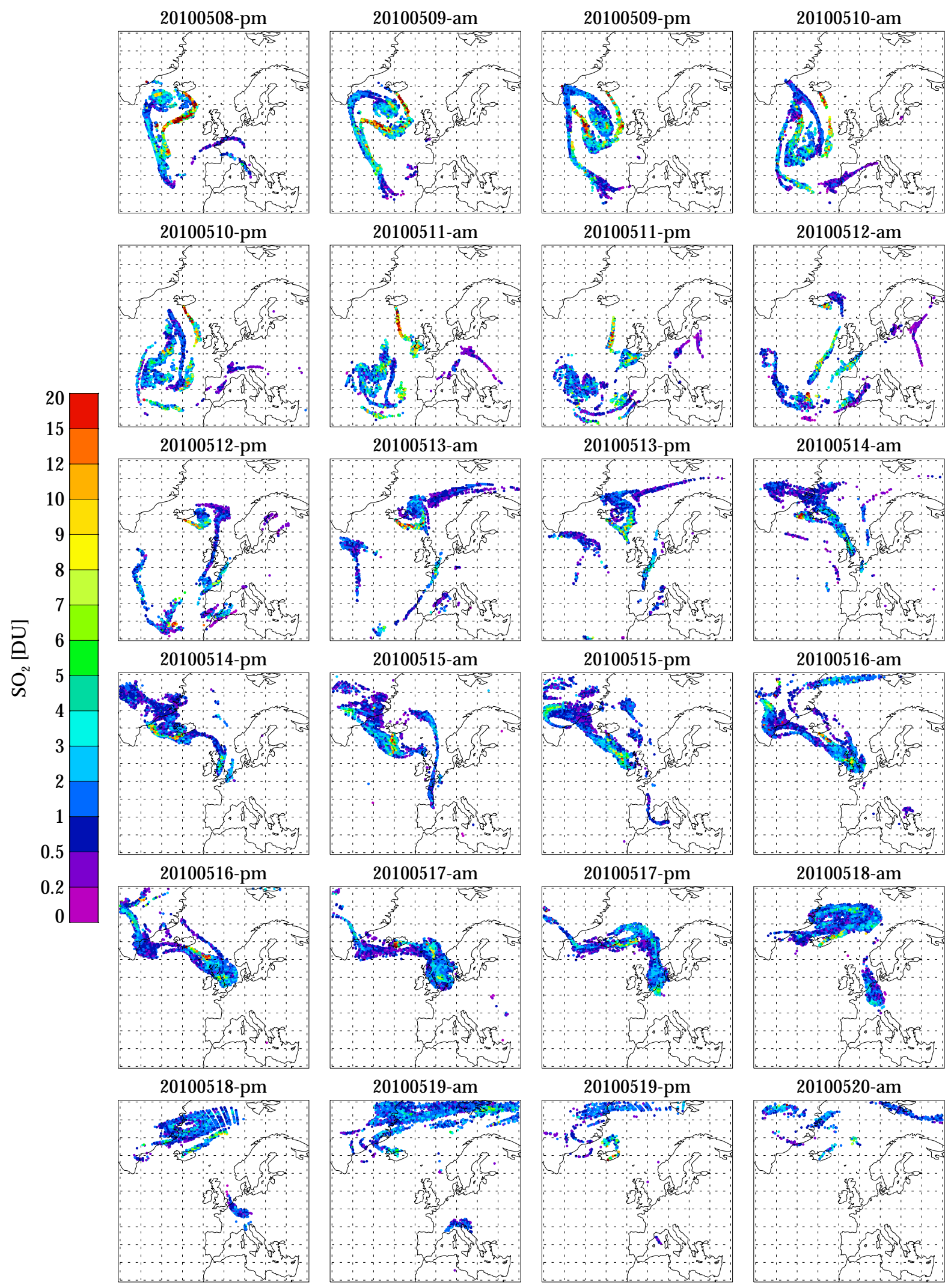

Fig. 9. IASI $\mathrm{SO}_{2}$ column amount, divided into morning and afternoon orbits, for the period from 8 to 17 May 2010 . 


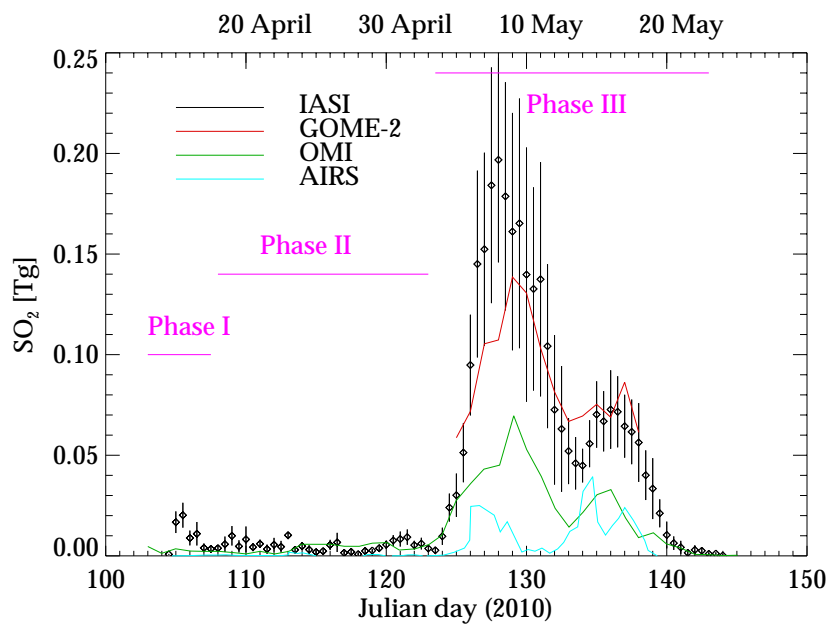

Fig. 10. Estimate of total mass of $\mathrm{SO}_{2}$ present in the Eyjafjallajökull plume: IASI data (and error bars) are shown in black, GOME-2 values (Rix et al., 2012) are shown in red, OMI values (Thomas and Prata, 2011) are shown in green, and finally AIRS values (Thomas and Prata, 2011) are shown in cyan.

IASI retrievals will be biased low. It is also worth noting that simultaneous measurements by GOME-2 (also on MetOp) generally show higher $\mathrm{SO}_{2}$ amounts than OMI and AIRS. More quantitative comparisons between different measurements in thick ash conditions are highly desirable but are beyond the scope of this paper.

\section{Conclusions and further work}

A new OE scheme has been developed for IASI measurements to estimate the height and column amount of a volcanic $\mathrm{SO}_{2}$ plume together with the associated pixel-by-pixel error estimates. The error covariance matrix is computed using the differences between the measured IASI spectra and the simulated spectra (driven by ECMWF data). This means that all the variability in the IASI signal, due to imperfect knowledge of non- $\mathrm{SO}_{2}$ atmospheric conditions (e.g. vertical distribution of constituents, cloudiness) as well as imperfect radiative transfer simulations (e.g. RTTOV approximations, spectroscopic errors), are included in the retrieval scheme. On the other hand the ash contamination is not included.

The error analysis indicates that: (i) the relative uncertainty in $\mathrm{SO}_{2}$ is higher for low amounts of $\mathrm{SO}_{2}$, (ii) the minimum error (0.2 DU) is obtained when the plume altitude is close to the tropopause (i.e. there is maximum thermal contrast between surface and plume) and it increases when the plume is nearer the surface.

The forward model includes the possibility of simulating an atmosphere with an ash or cloud layer. Cloud or thick ash at the same altitude, or above the plume, masks the $\mathrm{SO}_{2}$ signal and so the retrieval underestimates the $\mathrm{SO}_{2}$ amount. In most cases these conditions can be recognized through a posteriori quality control (i.e. elevated levels of the cost function). A retrieval of the ash parameters (optical depth, altitude and effective radius) is possible within this scheme but because of the high variability of ash refractive index within the thermal infrared spectral range was not considered here. Future work on this subject, together with an analysis of the $\mathrm{SO}_{2}$ retrieval performance in the presence of a thick ash plume, is desirable.

The results from a study of a medium intensity eruption, that of Eyjafjallajökull in 2010, illustrate that the scheme is able to follow the evolution of an $\mathrm{SO}_{2}$ plume thought all the eruptive periods and to quantify the $\mathrm{SO}_{2}$ amount and altitude, including where the intensity of the eruption and the altitude of the plume are lower.

The total $\mathrm{SO}_{2}$ amounts derived from IASI measurements were higher than OMI for eruption Phases I and III, comparable with OMI for the majority of Phase II, and consistent with GOME-2 for Phase III. It would be interesting to see if the discrepancies could be explained by the assumption made about plume height in OMI, AISR and COME-2 retrievals, or if other factors such as ash play a key role in producing the discrepancies.

Acknowledgements. E. Carboni and R. Grainger were supported by the NERC NCEO Dynamic Earth Geohazard theme (COMET+); J. Walker, A. Dudhia and R. Siddans were supported by the NERC NCEO Atmospheric Composition theme. The authors acknowledge Pieter Valks for GOME-2 data and Fred Prata for AIRS data and interesting discussions. Finally, the authors would like to thank Matthew Watson and the anonymous reviewer for their comments on the manuscript.

Edited by: F. Prata

\section{References}

Blumstein, D., Chalon, G., Carlier, T., Buil, C., Hébert, P., Maciaszek, T., Ponce, G., Phulpin, T., Tournier, B., Siméoni, D., PAstruc, Clauss, A., Kayal, G., and Jegou, R.: IASI Instrument: Technical overview and measured performances, Proc. SPIE, 5543, 196-207, 2004.

Bruhl, C. and Crutzen, P. J.: MPIC two-dimensional model, in: The atmospheric effects of stratospheric aircraft, vol. 1292 of Ref. Pub., 103-104, NASA, 1993.

Carboni, E. and Grainger, R.: Satellite remote sensing of $\mathrm{SO}_{2}$ volcanic emission using GOME-2 and IASI data: sensitivity analysis, in: Geophysical Research Abstracts, vol. 11, 2009.

Carn, S. A., Krueger, A. J., Bluth, G. J. S., Schaefer, S. J., Krotkov, N. A., Watson, I. M., and Datta, S.: Volcanic eruption detection by the Total Ozone Mapping Spectrometer (TOMS) instrument: a 22-year record of sulfur dioxide and ash emissions, in: Volcanic Degassing, edited by: Oppenheimer, C., Pyle, D. M., and Barclay, J., 213, 177-203, Geological Society, London, UK, 2003.

Carn, S. A., Strow, L. L., de Souza-Machado, S., Edmonds, Y., and Hannon, S.: Quantifying tropospheric volcanic emissions with 
AIRS: The 2002 eruption of Mt. Etna (Italy), Geophys. Res. Lett., 32, L02301, doi:10.1029/2004GL021034, 2005.

Carn, S. A., Krueger, A. J., Arellano, S., Krotkov, N. A., and Yang, K.: Daily monitoring of Ecuadorian volcanic degassing from space, J. Volcanol. Geoth. Res., 176, 141-150, doi:10.1016/j.jvolgeores.2008.01.029, 2008.

Clarisse, L., Coheur, P. F., Prata, A. J., Hurtmans, D., Razavi, A., Phulpin, T., Hadji-Lazaro, J., and Clerbaux, C.: Tracking and quantifying volcanic $\mathrm{SO}_{2}$ with IASI, the September 2007 eruption at Jebel at Tair, Atmos. Chem. Phys., 8, 7723-7734, doi:10.5194/acp-8-7723-2008, 2008.

Clarisse, L., Hurtmans, D., Clerbaux, C., Hadji-Lazaro, J., Ngadi, Y., and Coheur, P.-F.: Retrieval of sulphur dioxide from the infrared atmospheric sounding interferometer (IASI), Atmos. Meas. Tech., 5, 581-594, doi:10.5194/amt-5-581-2012, 2012.

Clerbaux, C., Coheur, P.-F., Clarisse, L., Hadji-Lazaro, J., Hurtmans, D., Turquety, S., Bowman, K., Worden, H., and Carn, S. A.: Measurements of $\mathrm{SO}_{2}$ profiles in volcanic plumes from the NASA Tropospheric Emission Spectrometer (TES), Geophys. Res. Lett., 35, L22807, doi:10.1029/2008GL035566, 2008.

Clerbaux, C., Boynard, A., Clarisse, L., George, M., Hadji-Lazaro, J., Herbin, H., Hurtmans, D., Pommier, M., Razavi, A., Turquety, S., Wespes, C., and Coheur, P.-F.: Monitoring of atmospheric composition using the thermal infrared IASI/MetOp sounder, Atmos. Chem. Phys., 9, 6041-6054, doi:10.5194/acp-9-6041-2009, 2009.

Corradini, S., Spinetti, C., Carboni, E., Tirelli, C., Buongiorno, M. F., Pugnaghi, S., and Gangale, G.: Mt. Etna tropospheric ash retrieval and sensitivity analysis using moderate resolution imaging spectroradiometer measurements, J. Appl. Remote Sens., 2, 023 550-023 550-20, doi:10.1117/1.3046674, 2008.

Corradini, S., Merucci, L., Prata, A. J., and Piscini, A.: Volcanic ash and $\mathrm{SO}_{2}$ in the 2008 Kasatochi eruption: retrievals comparison from different IR satellite sensors, J. Geophys. Res., 115, D00L21, doi:10.1029/2009JD013634, 2010.

European Commission: The Impact of the Volcanic Ash Cloud Crisis on the Air Transport Industry, SEC(2010) 533, 27 April, Brussels., 2010.

Francis, P. N., Cooke, M. C., and Saunders, R. W.: Retrieval of physical properties of volcanic ash using Meteosat: a case study from the 2010 Eyjafjallajökull eruption, J. Geophys. Res., 117, D00U09, doi:10.1029/2011JD016788, 2012.

Grainger, R. G., Peters, D. M., Thomas, G. E., Smith, A. J. A., Siddans, R., Carboni, E., and Dudhia, A.: Measuring Volcanic Plume and Ash Properties from Space, in Remote-sensing of Volcanoes and Volcanic Processes: Integrating Observation and Modelling, edited by: Pyle, D. M., Mather, T. A., and Biggs, J., The Geological Society Special Publication 380, in press, 2012.

Harrison, R. G., Nicoll, K. A., Ulanowski, Z., and Mather, T. A.: Self-charging of the Eyjafjallajökull volcanic ash plume, Environ. Res. Lett., 5, 024004, doi:10.1088/1748-9326/5/2/024004, 2010.

Henney, L., Rodríguez, L., and Watson, I.: A comparison of $\mathrm{SO}_{2}$ retrieval techniques using mini-UV spectrometers and ASTER imagery at Lascar volcano, Chile, B. Volcanol., 74, 589-594, 10.1007/s00445-011-0552-2, 2012.

Karagulian, F., Clarisse, L., Clerbaux, C., Prata, A. J., Hurtmans, D., and Coheur, P. F.: Detection of volcanic $\mathrm{SO}_{2}$, ash, and $\mathrm{H}_{2} \mathrm{SO}_{4}$ using the Infrared Atmospheric Sounding Interferometer (IASI),
J. Geophys. Res., 115, D00L02, doi:10.1029/2009JD012786, 2010.

Kearney, C. S. and Watson, I. M.: Correcting satellite-based infrared sulfur dioxide retrievals for the presence of silicate ash, J. Geophys. Res., 114, D22208, doi:10.1029/2008JD011407, 2009.

Marenco, F., Johnson, B., Turnbull, K., Newman, S., Haywood, J., Webster, H., and Ricketts, H.: Airborne lidar observations of the 2010 Eyjafjallajökull volcanic ash plume, J. Geophys. Res., 115, D00U05, doi:10.1029/2011JD016396, 2011.

Marzano, F. S., Lamantea, M., Montopoli, M., Di Fabio, S., and Picciotti, E.: The Eyjafjöll explosive volcanic eruption from a microwave weather radar perspective, Atmos. Chem. Phys., 11, 9503-9518, doi:10.5194/acp-11-9503-2011, 2011.

Matricardi, M.: The generation of RTTOV regression coefficients for IASI and AIRS using a new profile training set and a new line by line database, Tech. Memo. 564, ECMWF Research Dept., http://www.ecmwf.int/publications/ library/ecpublications/_pdf/tm/501-600/tm564.pdf, 2008.

Mazzocchi, M., Hansstein, F., and Ragona, M.: The 2010 Volcanic Ash Cloud and Its Financial Impact on the European Airline Industry, CESifo Forum, 11, 92-100, 2010.

Merucci, L., Burton, M., Corradini, S., and Salerno, G. G.: Reconstruction of SO2 flux emission chronology from spacebased measurements, J. Volcanol. Geoth. Res., 206, 80-87, doi:10.1016/j.jvolgeores.2011.07.002, 2011.

Mona, L., Amodeo, A., D’Amico, G., Giunta, A., Madonna, F., and Pappalardo, G.: Multi-wavelength Raman lidar observations of the Eyjafjallajökull volcanic cloud over Potenza, Southern Italy, Atmos. Chem. Phys., 12, 2229-2244, doi:10.5194/acp-12-22292012, 2012.

Nowlan, C. R., Liu, X., Chance, K., Cai, Z., Kurosu, T. P., Lee, C., and Martin, R. V.: Retrievals of sulfur dioxide from the Global Ozone Monitoring Experiment 2 (GOME-2) using an optimal estimation approach: algorithm and initial validation, J. Geophys. Res., 116, D18301, doi:10.1029/2011JD015808, 2011.

Petersen, G. N., Bjornsson, H., and Arason, P.: The impact of the atmosphere on the Eyjafjallajökull 2010 eruption plume, J. Geophys. Res., 117, D00U07, doi:10.1029/2011JD016762, 2012.

Poulsen, C. A., Siddans, R., Thomas, G. E., Sayer, A. M., Grainger, R. G., Campmany, E., Dean, S. M., Arnold, C., and Watts, P. D.: Cloud retrievals from satellite data using optimal estimation: evaluation and application to ATSR, Atmos. Meas. Tech., 5, 1889-1910, doi:10.5194/amt-5-1889-2012, 2012.

Prata, A. J. and Bernardo, C.: Retrieval of volcanic $\mathrm{SO}_{2}$ column abundance from atmospheric infrared sounder data, J. Geophys. Res., 112, D20204, doi:10.1029/2006JD007955, 2007.

Prata, A. J. and Kerkmann, J.: Simultaneous retrieval of volcanic ash and $\mathrm{SO}_{(2)}$ using MSG-SEVIRI measurements, Geophys. Res. Lett., 34, L05813, doi:10.1029/2006GL028691, 2007.

Prata, A. J., Rose, W. I., Self, S., and O'Brien, D. M.: Global, longterm sulphur dioxide measurements from TOVS data: A new tool for studying explosive volcanism and climate, in: Volcanism and the Earth's Atmosphere, edited by: Robock, A. and Oppenheimer, C., vol. 139 of Geophysical Monograph Series, American Geophysical Union, 75-92, doi:10.1029/GM139, 2003.

Prata, A. J., Gangale, G., Clarisse, L., and Karagulian, F.: Ash and sulphur dioxide in the 2008 eruptions of Okmok and Kasatochi: Insights from high spectral resolution satellite measurements, J. Geophys. Res., 115, D00L18, doi:10.1029/2009JD013556, 
2010.

Rauthe-Schöch, A., Weigelt, A., Hermann, M., Martinsson, B. G., Baker, A. K., Heue, K. P., Brenninkmeijer, C. A. M., Zahn, A., Scharffe, D., Eckhardt, S., Stohl, A., and van Velthoven, P. F. J.: CARIBIC aircraft measurements of Eyjafjallajökull volcanic clouds in April/May 2010, Atmos. Chem. Phys., 12, 879902, doi:10.5194/acp-12-879-2012, 2012.

Realmuto, V. J.: The potential use of Earth Observing System data to monitor the passive emission of sulfur dioxide from volcanoes, Geoph. Monog. Series, 116, 101-115, 2000.

Realmuto, V. J., Abrams, M. J., Buongiornio, M. F., and Pieri, D. C.: The use of multispectral thermal infrared image data to estimate the sulfur dioxide flux from volcanoes: a case study from Mount Etna, Sicily, 29 July 1986, J. Geophys. Res., 99, 481-488, 1994.

Realmuto, V. J., Sutton, A. J., and Elias, T.: Multispectral imaging of sulfur dioxide plumes from the East Rift Zone of Kilauea Volcano, Hawaii, J. Geophys. Res., 102, 15057-15072, 1997.

Rix, M., Valks, P., Hao, N., Loyola, D. G., Schlager, H., Huntrieser, H. H., Flemming, J., Koehler, U., Schumann, U., and Inness, A.: Volcanic $\mathrm{SO}_{2}, \mathrm{BrO}$ and plume height estimations using GOME-2satellite measurementsduring the eruption of Eyjafjallajökull in May 2010, J. Geophys. Res., 117, D00U19, doi:10.1029/2011JD016718, 2012.

Rodgers, C. D.: Inverse Methods for Atmospheric Sounding: Theory and Practice, World Scientific, River Edge, NJ, USA, 2000.

Rozanov, V., Diebel, D., Spurr, R. J. D., and Burrows, J. P.: GOMETRAN: a radiative transfer model for the satellite project GOME - the plane parallel version, J. Geophys. Res., 102, 16683-16696, 1997.

Saunders, R. W., Matricardi, M., and Brunel, P.: An improved fast radiative transfer model for assimilation of satellite radiance observations, Q. J. Roy. Meteor. Soc., 125, 1407-1425, 1999.

Schumann, U., Weinzierl, B., Reitebuch, O., Schlager, H., Minikin, A., Forster, C., Baumann, R., Sailer, T., Graf, K., Mannstein, H., Voigt, C., Rahm, S., Simmet, R., Scheibe, M., Lichtenstern, M., Stock, P., Rüba, H., Schäuble, D., Tafferner, A., Rautenhaus, M., Gerz, T., Ziereis, H., Krautstrunk, M., Mallaun, C., Gayet, J.F., Lieke, K., Kandler, K., Ebert, M., Weinbruch, S., Stohl, A., Gasteiger, J., Groß, S., Freudenthaler, V., Wiegner, M., Ansmann, A., Tesche, M., Olafsson, H., and Sturm, K.: Airborne observations of the Eyjafjalla volcano ash cloud over Europe during air space closure in April and May 2010, Atmos. Chem. Phys., 11, 2245-2279, doi:10.5194/acp-11-2245-2011, 2011.

Sears, T. M., Thomas, G. E., Carboni, E., Smith, A., and Grainger, R. G.: $\mathrm{SO}_{2}$ as a proxy for volcanic ash in aviation hazard avoidance, J. Geophys. Res., under review, 2012.
Stamnes, K., Tsay, S. C., Wiscombe, W., and Jayaweera, K.: Numerically stable algorithm for discrete-ordinate-method radiative transfer in multiple scattering and emitting layered media, Appl. Opt., 27, 2502-2509, 1988.

Stevenson, J. A., Loughlin, S., Rae, C., Thordarson, T., Milodowski, A. E., Gilbert, J. S., Harangi, S., Lukács, R., Højgaard, B., Árting, U., Pyne-O’Donnell, S., MacLeod, A., Whitney, B., and Cassidy, M.: Distal deposition of tephra from the Eyjafjallajökull 2010 summit eruption, J. Geophys. Res., 117, B00C10, doi:10.1029/2011JB008904, 2012.

STFC: Fast transmittance modelling of the MSG and MTG solar channels for cloud retrievals, Tech. rep., Rutherford Appleton Laboratory, Chilton, Didcot OX11 0QX, UK, http://www.eumetsat.int/groups/ops/documents/document/ pdf_report_fast_trans.pdf, 2011.

Stohl, A., Prata, A. J., Eckhardt, S., Clarisse, L., Durant, A., Henne, S., Kristiansen, N. I., Minikin, A., Schumann, U., Seibert, P., Stebel, K., Thomas, H. E., Thorsteinsson, T., Tørseth, K., and Weinzierl, B.: Determination of time- and height-resolved volcanic ash emissions and their use for quantitative ash dispersion modeling: the 2010 Eyjafjallajökull eruption, Atmos. Chem. Phys., 11, 4333-4351, doi:10.5194/acp-11-4333-2011, 2011.

Symonds, R. B., Rose, W. I., Bluth, G., and Gerlach, T. M.: Volcanic-gas studies: methods, results, and applications, Rev. Mineral. Geochem., 30, 1-66, 1994.

Thomas, H. E. and Prata, A. J.: Sulphur dioxide as a volcanic ash proxy during the April?May 2010 eruption of Eyjafjallajökull Volcano, Iceland, Atmos. Chem. Phys., 11, 6871-6880, doi:10.5194/acp-11-6871-2011, 2011.

Thomas, H. E., Watson, I. M., Kearney, C., Carn, S. A., and Murray, S. J.: A multi-sensor comparison of sulphur dioxide emissions from the 2005 eruption of Sierra Negra volcano, Galapagos Islands, Remote Sens. Environ., 113, 1331-1342, 2009.

Walker, J. C., Dudhia, A., and Carboni, E.: An effective method for the detection of trace species demonstrated using the MetOp Infrared Atmospheric Sounding Interferometer, Atmos. Meas. Tech., 4, 1567-1580, doi:10.5194/amt-4-1567-2011, 2011.

Walker, J. C., Carboni, E., Dudhia, A., and Grainger, R. G.: Improved detection of sulphur dioxide in volcanic plumes using satellite-based hyperspectral infra-red measurements: application to the Eyjafjallajökull 2010 eruption, J. Geophys. Res., 117, D00U16, doi:10.1029/2011JD016810, 2012.

Zehner, C., ed.: Monitoring Volcanic Ash from Space. Proceedings of the ESA-EUMETSAT workshop on the 14 April to 23 May 2010 eruption at the Eyjafjoll volcano, South Iceland, ESA STM280, European Space Agency, doi:10.5270/atmch-10-01, 2012. 